\title{
Running hot and cold: behavioral strategies, neural circuits, and the molecular machinery for thermotaxis in C. elegans and Drosophila
}

\author{
Paul A. Garrity, ${ }^{1,2,5}$ Miriam B. Goodman, ${ }^{3}$ Aravinthan D. Samuel, ${ }^{4}$ and Piali Sengupta ${ }^{1,2,6}$ \\ ${ }^{1}$ Department of Biology, Brandeis University, Waltham, Massachusetts 02454, USA; ${ }^{2}$ National Center for Behavioral Genomics, \\ Brandeis University, Waltham, Massachusetts 02454, USA; ${ }^{3}$ Department of Molecular and Cellular Physiology, Stanford \\ University, Stanford, California 94305, USA; ${ }^{4}$ Department of Physics and Center for Brain Science, Harvard University, \\ Cambridge, Massachusetts 02138, USA
}

Like other ectotherms, the roundworm Caenorhabditis elegans and the fruit fly Drosophila melanogaster rely on behavioral strategies to stabilize their body temperature. Both animals use specialized sensory neurons to detect small changes in temperature, and the activity of these thermosensors governs the neural circuits that control migration and accumulation at preferred temperatures. Despite these similarities, the underlying molecular, neuronal, and computational mechanisms responsible for thermotaxis are distinct in these organisms. Here, we discuss the role of thermosensation in the development and survival of $C$. elegans and Drosophila, and review the behavioral strategies, neuronal circuits, and molecular networks responsible for thermotaxis behavior.

The ability to sense and respond to ambient temperature is crucial for the survival and fitness of all animals. Endotherms such as birds and mammals maintain a relatively constant body temperature regardless of ambient temperature via a number of mechanisms, including behavioral modification, as well as central regulation of autonomic nervous system functions (Hensel 1973; Simon et al. 1986). However, for ectotherms like Caenorhabditis elegans and Drosophila melanogaster, whose body temperature varies with ambient temperature, behavioral strategies are the primary mechanism for regulating optimal internal temperature (Stevenson 1985; Huey et al. 2003). In this review, we describe the known neuronal and molecular strategies used by C. elegans and Drosophila to detect and behaviorally respond to changes in temperature, focusing particularly on temperature-

[Keywords: C. elegans; Drosophila; TRP; cGMP; thermosensory; thermotaxis]

${ }^{5}$ Authors are listed alphabetically.

${ }^{6}$ Corresponding author.

E-MAIL sengupta@brandeis.edu; FAX (781) 736-3107.

Article is online at http://www.genesdev.org/cgi/doi/10.1101/gad.1953710. guided behaviors that operate within each animal's normal thermal zone.

\section{A note on terminology}

Various terms have been used to describe patterns of thermotactic movement in C. elegans and Drosophila. For instance, worms moving down temperature gradients toward cooler temperatures are said to be "cryophilic" (Fig. 1A), while the same behavior executed by flies is called "warmth avoidance." By the same logic, movements up temperature gradients have been called "thermophilic" in worms and "cold avoidance" behavior in flies (Fig. 1B). Here, movement down and up temperature gradients will be referred to as "negative thermotaxis" and "positive thermotaxis," respectively. In addition to positive and negative thermotaxis, worms have a robust tendency to move along isothermal contours when they are near their preferred temperature, a behavior referred to as "isothermal tracking" (Fig. 1E). Isothermal tracking has not been observed in flies.

The ethology of thermotaxis in C. elegans and D. melanogaster

Temperature is an environmental variable that affects the rate and nature of all chemical reactions, and hence has dramatic effects on animal physiology. At the extremes of the temperature spectrum, exposure to excessive heat or cold causes dramatic perturbations in cellular physiology that rapidly lead to the failure of nervous system function and to serious tissue damage. Thus, thermal nociception-the ability to sense and respond to noxious heat and noxious cold-is critical for animal survival (Tominaga and Caterina 2004).

Even at more moderate temperatures, thermal variations affect animal physiology. Thus, thermotaxis-the ability to migrate up or down a temperature gradient-also makes a critical contribution to an animal's fitness. Thermotaxis 
A

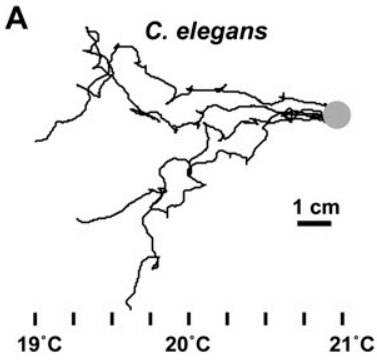

B

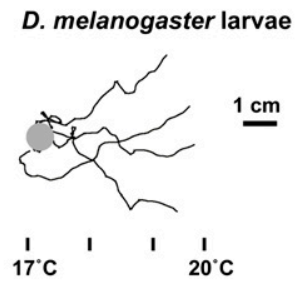

C

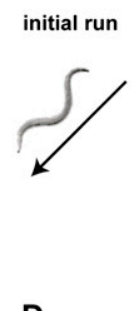

D

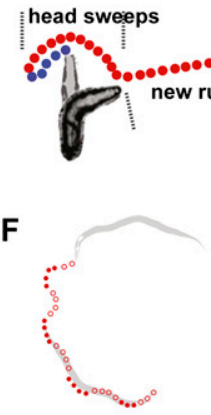

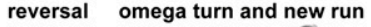
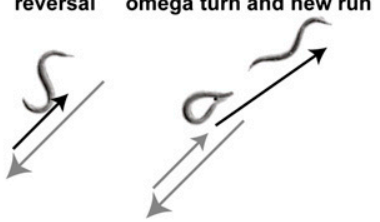

E

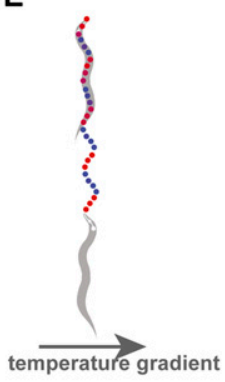

G

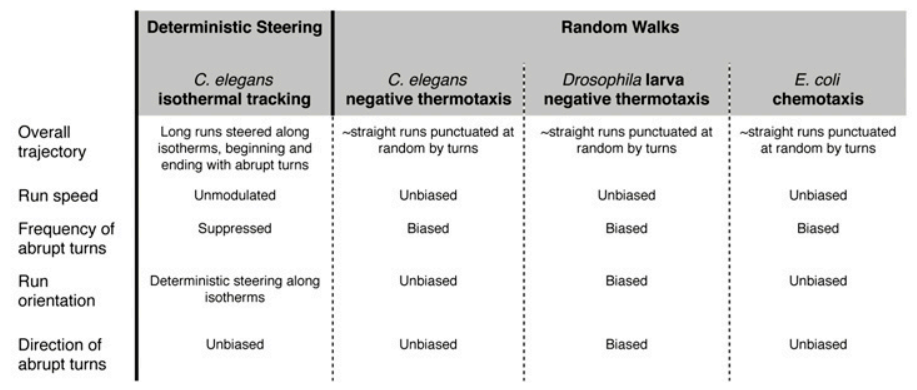

Figure 1. Stochasticity, determinism, and decisionmaking in C. elegans and Drosophila thermotaxis. $(A, B)$ Biased random walks. Trajectories of individual C. elegans nematodes or D. melanogaster larvae are intrinsically stochastic, resembling biased random walks when viewed at low magnification. Each trajectory is marked by periods of forward movement (runs) interrupted by abrupt reorientation maneuvers (turns). (A) Trajectories of four worms grown at $15^{\circ} \mathrm{C}$ and placed on a temperature gradient above $T_{c}$. All worms exhibit negative thermotaxis, but no two trajectories are alike. (B) Trajectories of four Drosophila larvae exhibiting positive thermotaxis moving from below preferred temperature toward warmer temperatures. (Gray circles) Starting points. $(C)$ Unbiased reorientation in C. elegans. The initial run, in which the worm is headed to the lower left, is terminated by a reversal. The reversal is terminated by an $\Omega$ turn. Following the $\Omega$ turn, the worm starts a new run in a new direction. The worm biases its random walk by regulating the frequency of these abrupt turns, depending on direction with respect to the surrounding temperature gradient. Runs are lengthened toward preferred temperatures and shortened away from preferred temperatures. $(D)$ Biased reorientation in $D$. melanogaster. During each reorientation maneuver, a Drosophila larva will pause and deliberately swing its head back and forth. If the larva happens to be isothermally aligned, it will encounter falling temperatures if it moves its head in one direction (illustrated by blue dots that trace the trajectory of the thermosensory neurons at the larva's head) and rising temperatures if it moves its head in the other direction (the trace of red dots). The larva biases the probability of starting a new run based on the temperature it encounters during each head sweep. Thus, after being isothermally aligned, the larva tends to start new runs toward the larva's preferred temperature. (E) C. elegans steers in a deterministic manner to maintain isothermal alignment when near its $T_{c}$ (isothermal tracking). During isothermal tracking, C. elegans continuously swings its head back and forth; thus, the thermosensory neurons at its head encounter regular and alternating phases of falling temperature (blue dots) and rising temperature (red dots). The worm uses this sinusoidal variation in temperature to correct the curvature of its undulation, veering its nose away from every temperature variation and stabilizing isothermal alignment to within $\sim 0.01^{\circ} \mathrm{C}$. $(F)$ When C. elegans is exposed to positive temperature pulses when it swings its head to one side (filled red dots) but not the other side (open red dots), it curves its overall trajectory away from the thermal stimulation. (G) Comparison of behavioral strategies that govern C. elegans thermotaxis, D. melagnoster larval thermotaxis, and Escherichia coli chemotaxis.

is especially important in small ectotherms such as $C$. elegans and Drosophila, whose small mass (e.g., adult flies are $<2 \mathrm{mg}$ ) means they have small heat capacities. Thus, internal structures readily equilibrate to the temperature of their surroundings (Stevenson 1985; Heinrich 1993). When considering how rapidly this occurs, it is important to consider the distances over which thermal energy must travel to reach internal structures. The time scale of the equilibration of internal structures in response to changes in surface temperature can be estimated as the time at which the root mean square of thermal diffusion equals the distance from the animal's surface to its innermost point. This value can be estimated using a one-dimensional diffusion equation (root mean distance $)^{2}=2 \mathrm{D} t$, where $\mathrm{D}$ is the thermal diffusivity of water $\left(\sim 0.15 \mathrm{~mm}^{2}\right.$ per second) (Noroozi et al. 2009) and $t$ is time. As both first instar $D$. melanogaster larvae and adult $C$. elegans nematodes are $\leq 0.1 \mathrm{~mm}$ in diameter, the time scale of the equilibration of their most internal structures in response to changes in surface temperature is less than a tenth of a second. Even D. melanogaster third instar larvae and adult flies are only $1-1.25 \mathrm{~mm}$ thick, leading to a predicted equilibration of their most internal structures within a few seconds. Such rapid equilibration with their environment suggests that behavioral strategies for seeking out appropriate environments are paramount for body temperature control in these organisms. Moreover, this suggests that, in contrast to endotherms and larger ectotherms such as reptiles, thermal sensors need not be located on the body surface to respond rapidly to external temperature changes, but could instead be positioned internally.

The sensitivity of fly and nematode body temperature to environmental temperature changes is paralleled by the striking sensitivity of their thermosensory systems. In discussing thermosensory mechanisms, we distinguish between the ordinary temperature dependence shared by 
all cellular processes and the extraordinary temperature dependence of specialized thermosensory neurons. Both $D$. melanogaster and C. elegans thermosensory systems are capable of driving thermotaxis in response to temperature fluctuations of $<0.005^{\circ} \mathrm{C} / \mathrm{sec}$ (Clark et al. 2006; Luo et al. 2006, 2010). Such sensitivity rivals the famed thermal sensitivity of the infrared detectors of pit vipers, which have been estimated to detect fluctuations of $\sim 0.001^{\circ} \mathrm{C} / \mathrm{sec}$ (Bullock and Diecke 1956). Interestingly, the thermal pits of vipers are used not only for hunting prey, but also for thermotaxis to regulate body temperature (Krochmal and Bakken 2003).

If the main effect of thermotaxis on fitness is mediated through the regulation of body temperature control, a reasonable question is how precisely flies and worms must control their body temperatures in order to survive. At a coarse level, extremes of both heat and cold directly damage living tissue by compromising cellular integrity and denaturing key cellular components. But, at a subtler level, all biochemical processes-from enzymatic reactions to the flow of ions through channels-are affected by temperature. Thus, physiological systems can become suboptimal at temperatures that do not immediately compromise cellular integrity. Both D. melanogaster and C. elegans tolerate large temperature fluctuations; both species are able to survive and reproduce over environmental temperature ranges of $>15^{\circ} \mathrm{C}$ (Harvey and Viney 2007; Hoffmann 2010). Such tolerance for temperature fluctuation is clearly a key element in their success as ectotherms, and work to date suggests that the range of tolerated temperatures is a critical factor in determining geographic distributions, at least of flies (Hoffmann 2010). However, within the animal's normal thermal zone, each species grows most robustly at specific temperatures. $D$. melanogaster exhibit maximal growth rates near $24^{\circ} \mathrm{C}$ (Siddiqui and Barlow 1972; Hoffmann 2010), while the lifetime fecundity of multiple independent isolates of $C$. elegans nematodes, including the common Bristol N2 laboratory strain, declines above $\sim 19^{\circ} \mathrm{C}$ (Harvey and Viney 2007). Thus, maintaining body temperature within a narrow optimum range is likely to be important for maximizing their fitness in the wild.

When considering the ecological impact of thermotaxis on animal fitness, it is important to appreciate that the optimal body temperature for a given organism need not be fixed, but is potentially dynamic, changing as a function of both environmental and developmental factors. Indeed, significant plasticity has been observed in the value of the preferred temperature in response to multiple factors. While humidity levels and food affect thermotactic behavior (Hedgecock and Russell 1975; Dillon et al. 2009), the most widely studied environmental factor regulating temperature preference behavior is the cultivation temperature $\left(T_{c}\right)$. In $C$. elegans, adult nematodes reset their set point for thermotaxis in response to changes in $T_{c}$ over a period of a few hours (Hedgecock and Russell 1975; see further discussion below). Although D. melanogaster lack such short-term plasticity, altering the temperature at which flies develop can significantly alter thermal preference (Krstevska and Hoffmann 1994).
Interestingly, unlike C. elegans nematodes, which reset their thermotaxis thresholds toward $T_{c}$, flies raised at a high temperature $\left(29^{\circ} \mathrm{C}\right)$ prefer $\sim 3^{\circ} \mathrm{C}$ cooler temperatures than flies raised at lower temperatures $\left(19^{\circ} \mathrm{C}\right.$ and $25^{\circ} \mathrm{C}$ ) (Krstevska and Hoffmann 1994).

While the functional significance of the long-term, developmental temperature-dependent change in thermal preference observed in flies remains unclear, recent work indicates that short-term temperature-dependent changes make an important contribution to the maintenance of favorable body temperatures in the laboratory $\mathrm{N} 2$ strain of C. elegans (Ramot et al. 2008b). As discussed below, N2 exhibits robust negative thermotaxis, but exhibits positive thermotaxis only under defined conditions (Ito et al. 2006; Ramot et al. 2008b; Jurado et al. 2010). Using simulations that incorporate measured nematode behavioral parameters and soil temperature fluctuations, a strategy involving only negative thermotaxis was found to drive worms progressively deeper into the soil until thermal gradients become too small to drive further changes. However, plasticity in the memory of $T_{c}$ that drives thermotaxis allows worms to continually readjust their behavior, optimizing their time at favorable body temperatures and maintaining their position at a consistent and favorable soil depth (Ramot et al. 2008b). Furthermore, such plasticity also provides significant robustness in the face of genetic and environmental variation (Ramot et al. 2008b). Many ectotherms, including flies, do not exhibit such rapid plasticity in their thermotactic behavior, but do possess a combination of strong negative and positive thermotaxis. It will be of interest to compare the strengths and weaknesses of these alternative approaches to thermoregulation.

In addition to environmental factors, developmental stage has a dramatic effect on preferred temperature behavior, at least in Drosophila. While first instar larvae prefer temperatures between $\sim 23^{\circ} \mathrm{C}$ and $\sim 29^{\circ} \mathrm{C}$ (Luo et al. 2010), the preference of third instar larvae drops significantly to $\sim 18^{\circ} \mathrm{C}$ (Ainsley et al. 2008; Kwon et al. 2008) (L Webb and P Garrity, unpubl.). This transition could be linked to the fact that third instar larvae stop feeding and begin to search for a site for pupariation. Identification of pupariation site is essential for survival, since the immobile pupa is unable to behaviorally thermoregulate for several days. This phenomenon is not unique to $D$. melanogaster; a similar developmental shift in larval thermotactic preference was reported in the housefly Musca domestica $\sim 70$ years ago (Thomsen and Thomsen 1937; Deal 1941). Eggs and early embryos are also immobile and unable to behaviorally thermoregulate; in this context, it will be interesting to know whether oviposition shows a similar cold shift in thermal preference (Dillon et al. 2009).

\section{Quantification of thermotactic behavior in C. elegans and Drosophila}

In classical laboratory assays of thermotaxis, worms or flies are placed in a spatial temperature gradient and allowed to explore for a fixed period of time, and accumulation is 
measured at the assay endpoints. Such assays allowed Hedgecock and Russell (1975) to demonstrate that worms aggregate near the temperature at which they were grown, indicating that the temperature preference of $C$. elegans is experience-dependent. Similar assays reveal that fruit flies lack such short-term plasticity, but instead show a preference for a fixed temperature in the mid- $20^{\circ} \mathrm{C}$ range (Krstevska and Hoffmann 1994; Sayeed and Benzer 1996).

While accumulation assays of thermotactic behavior are easy to implement and have been productive for identifying molecules and cells required for thermotaxis (see below), they are blunt tools for dissecting the workings of the underlying neuronal machinery. Animals follow specific rules of thermotactic strategy to navigate to their preferred temperature (see Fig. 1). Since failure to aggregate near the preferred temperatures may occur due to disruption of one or more components of these strategies, the defective components cannot easily be distinguished in these assays. Understanding the navigational strategy requires the identification of the type and outcome of each navigational decision that is made by an animal along a thermotactic trajectory, as well as an understanding of the rules by which sensory information is used to initiate and execute each navigational decision. In other words, the thermotactic performance of individual animals must be quantified during the navigational task.

Recent years have seen enormous progress in tracking systems that quantify the behavioral responses of small animals like C. elegans and Drosophila as they respond to defined chemical, visual, and thermal cues (e.g., PierceShimomura et al. 1999; Luo et al. 2006, 2008, 2010; Katsov and Clandinin 2008; Louis et al. 2008; Duistermars et al. 2009; Fry et al. 2009). In this section, we focus on quantitative behavioral analyses of thermotactic navigation in C. elegans and Drosophila, and how these analyses have advanced our understanding of the neural strategies that encode navigational decision making in these animals.

\section{Different modes of thermotaxis in C. elegans}

In their classic study, Hedgecock and Russell (1975) identified three modes of thermotactic movement: positive thermotaxis (exhibited below $T_{c}$ ), negative thermotaxis (exhibited above $T_{c}$ ), and isothermal tracking (near $T_{c}$ ). Mori and Ohshima (1995) showed that a small group of interconnected neurons-the bilateral AFD sensory neurons, as well as the bilateral AIY, AIZ, and RIA interneurons-are involved in the three modes of thermotactic movement. A popular model that assigns functional roles to these neurons is that worm thermotaxis results from the interaction of two opposing drives: a "thermophilic drive" involving AFD and AIY that impels the worm toward warm temperatures, a "cryophilic drive" involving AIZ that impels the worm toward cold temperatures, and a downstream comparator of the two drives involving RIA that guides behavior to the preferred temperature (Mori and Ohshima 1995).

However, recent experiments make it difficult to interpret worm behavior near $T_{c}$ as simply reflecting a balance between the behaviors above or below $T_{c}$. First, the behavior at $T_{c}$ (isothermal tracking) involves a distinct sensorimotor transformation that is neither positive nor negative thermotaxis (Ryu and Samuel 2002; Luo et al. 2006; Clark et al. 2007b). Second, whereas negative thermotaxis at temperatures above $T_{c}$ is robust and occurs in a variety of conditions, positive thermotaxis below $T_{c}$ occurs in only a narrow range of conditions (Hedgecock and Russell 1975; Mori and Ohshima 1995; Ramot et al. 2008b; Jurado et al. 2010). Third, isothermal tracking and negative thermotaxis may be mechanistically distinct, as mutations can be found that cause worms to exhibit negative thermotaxis both above and below $T_{c}$ without affecting isothermal tracking near $T_{c}$ (Colosimo et al. 2004). It remains an intriguing and largely unanswered question how a small circuit, using thermosensory information from the AFD neurons, is endowed with the flexibility to drive the distinct sensorimotor transformations that underlie different modes of thermotactic movement in different temperature ranges. These modes are reviewed below and summarized in Figure 1G.

Isothermal tracking in C. elegans When navigating spatial temperature gradients near their $T_{c}$, worms track isotherms (Fig. 1E; Hedgecock and Russell 1975). During isothermal tracking, worms veer by only $\sim 0.1^{\circ} \mathrm{C}$ during single long runs that can last several minutes. (In contrast, runs last $\sim 20 \mathrm{sec}$ on average in isotropic environments [Luo et al. 2006]). Because each worm tracks only isotherms within $\sim 2^{\circ} \mathrm{C}$ of its $T_{c}$ (Ryu and Samuel 2002; Luo et al. 2006), quantifying isothermal tracking behavior is an effective way of quantifying the worm's preferred temperature (Biron et al. 2006; Chi et al. 2007).

Because worms will often spontaneously stop tracking one isotherm and subsequently track another isotherm at a different temperature, isothermal tracking is likely to be a process that minimizes temperature fluctuations within a specific range of absolute temperatures (Ryu and Samuel 2002; Luo et al. 2006). Isothermal tracking behavior requires the AFD thermosensory neurons (Mori and Ohshima 1995). Moreover, thermosensation is localized to the sensory endings of the AFD neurons near the worm's nose (Coburn and Bargmann 1996; Komatsu et al. 1996; Clark et al. 2006; Inada et al. 2006). As the worm undulates along each isotherm on a spatial gradient, it moves the tip of its nose, where the thermosensory apparatus is located, from side to side with each undulation cycle. Each isothermal track is one long run without sharp $\Omega$ turns, so, to maintain isothermal alignment, the worm must be continuously executing small corrections to its heading. Luo et al. (2006) showed that a worm can maintain isothermal alignment in spatial gradients by simply augmenting the curvature of its own undulation to offset any temporal variation in temperature measured at its nose.

A sophisticated technique to explore the type of sensorimotor transformation used during isothermal tracking was developed recently by Stephens et al. (2008). While moving its nose from side to side during an isothermal track, the worm generates alternating warming 
and cooling phases in the AFD thermosensory signal that it acquires. Stephens et al. (2008) used a high-resolution tracking system to follow the movements of individual animals. Their system also delivered small, brief temperature pulses whenever the worm's nose moved to either side of its overall undulatory trajectory. Using this integrated tracking and temperature pulse delivery system, Stephens et al. (2008) found the worms would curve the direction of runs away from the side to which temperature pulses were delivered, a type of steering that is consistent with the proposed strategy for isothermal tracking (Fig. 1F). A related strategy called "weathervaning" is a component of chemotactic behavior. During weathervaning, the worm gradually bends the direction of each run toward the preferred direction up or down a concentration gradient of $\mathrm{NaCl}$ (Iino and Yoshida 2009).

Negative thermotaxis in C. elegans When placed on a temperature gradient at any temperature above $T_{c}$ and steeper than $\sim 0.1 \mathrm{C} / \mathrm{cm}$, worms migrate down temperature gradients toward $T_{c}$ (Fig. 1 $\mathrm{A}_{\text {; }}$ Hedgecock and Russell 1975; Mori and Ohshima 1995). In isotropic environments, the trajectory of each crawling worm resembles an unbiased random walk, with alternating periods of forward movement that are interrupted by abrupt reorientations (reversals and/or $\Omega$ turns), similar to the trajectory of a particle undergoing Brownian movement (Fig. 1C,G; Ryu and Samuel 2002; Zariwala et al. 2003). During negative thermotaxis, worms bias this random walk toward colder temperatures. If a worm happens to be moving toward colder/warmer temperatures during each run, it will lower/raise the likelihood of exhibiting a turn, thereby lengthening/shortening runs.

To execute a biased random walk, worms must determine their own orientation with respect to the surrounding temperature gradient, determine when they are headed up or down a temperature gradient, and promote or inhibit turn occurrence, accordingly. As in isothermal tracking, the worm responds to temperature gradients during negative thermotaxis via temporal variations in temperature. Heating or cooling a worm in a spatially uniform manner will raise and lower the rate of spontaneous turns, respectively (Ryu and Samuel 2002; Clark et al. 2007b; Ramot et al. 2008b)

Positive thermotaxis in C. elegans Hedgecock and Russell (1975) as well as Mori and Ohshima (1995) reported that worms, when grown at $25^{\circ} \mathrm{C}$, will aggregate at $25^{\circ} \mathrm{C}$ on a spatial temperature gradient, and also reported "thermophilic" phenotypes of worms that aggregate (because of either mutations or laser ablation of specific neurons) at the warmest temperatures on a gradient, irrespective of $T_{c}$ (Okochi et al. 2005). However, in most conditions, worms appear to be atactic at temperatures below $T_{c}$ (Ryu and Samuel 2002; Yamada and Ohshima 2003; Ramot et al. 2008b). Recent analyses suggest that positive thermotaxis is exhibited only under a restricted set of conditions (Ito et al. 2006; Ramot et al. 2008b; Jurado et al. 2010). Worms grown at $25^{\circ} \mathrm{C}$ will exhibit active movement up temperature gradients only within a narrow range of temperatures $\left(20^{\circ} \mathrm{C}-23^{\circ} \mathrm{C}\right)$ and only on gradients shallower than $0.5^{\circ} \mathrm{C} / \mathrm{cm}$. It is unclear why positive thermotaxis is limited to a narrow range of absolute temperatures and temperature gradients, while negative thermotaxis occurs under a wide range of conditions. The thermotactic strategy that the worm uses during positive thermotaxis remains to be identified.

\section{Negative and positive thermotaxis in Drosophila larvae}

Unlike C. elegans, the behavior of D. melanogaster first instar larvae exhibits a striking mirror symmetry above and below their preferred temperature of $\sim 24^{\circ} \mathrm{C}-28^{\circ} \mathrm{C}$ (Luo et al. 2010). Like C. elegans, the movements of crawling larvae consist of a highly stereotyped sequence of periods of forward movement interrupted by abrupt reorientation maneuvers or turns (Fig. 1B,G). During each period of forward movement, the larva regulates the likelihood of initiating each turn on the basis of thermosensory input. During each turn, a larva will pause and actively move its head from side to side until it selects a new direction for its subsequent forward movement on the basis of thermosensory input (Fig. 1D).

As in C. elegans, decision making during larval thermotaxis can be reduced to specific sensorimotor transformations. When navigating at temperatures below $\sim 20^{\circ} \mathrm{C}$, the larva uses its strategy for positive thermotaxis (Fig. 1B). When navigating at temperatures above $\sim 30^{\circ} \mathrm{C}$, the larva uses its strategy for negative thermotaxis. To enact either negative thermotaxis or positive thermotaxis, the larva relies on distinct sets of thermosensory neurons located in the larva's anterior (see below). Because the larva has spatially localized thermosensors for positive and negative thermotaxis, it relies on temporal thermosensory signals driven by the larva's self-movement in spatial temperature gradients, whether during each period of forward movement or the side-to-side movements that characterize each reorientation maneuver.

In isotropic environments, the durations of periods of forward movements and the angular changes evoked by reorientation maneuvers are stochastic. In temperature gradients, the larva biases the likelihood of starting a new reorientation maneuver during each period of forward movement on the basis of temporal variations in temperature. During positive/negative thermotaxis, if the larva encounters rising/falling temperatures over time, it postpones reorientation maneuvers, thus lengthening runs toward the preferred temperature (Fig. $1 \mathrm{~F}$; Luo et al. 2010). Thus, as in negative thermotaxis in $C$. elegans, the larva is capable of biasing a random walk toward preferred temperatures.

Unlike negative thermotaxis in C. elegans, the angular changes evoked by reorientation maneuvers in spatial temperature gradients tend to be toward the preferred temperature in Drosophila larvae (Fig. 1D,G). This can also be interpreted as a type of bias in a stochastic sensorimotor transformation. Each reorientation maneuver is characterized by side-to-side head sweeps. In temperature gradients, the direction of each head sweep is random, and 
can be to either the left or the right (Luo et al. 2010). However, the likelihood of starting a new forward movement during each head sweep is biased by thermosensory input during that head sweep. During negative/positive thermotaxis, the likelihood of starting a new forward movement is lowered/raised if the larva encounters falling temperatures during a particular head sweep (Luo et al. 2010). Because the final direction of the head during each head sweep defines the direction of the new run, the bias in initiating new runs generates a larger fraction of runs in the preferred direction for either mode of thermotaxis.

\section{Thermotaxis in adult Drosophila}

Adult Drosophila also prefer temperatures in the $24^{\circ} \mathrm{C}-$ $26^{\circ} \mathrm{C}$ range (Sayeed and Benzer 1996; Lee et al. 2005; Hamada et al. 2008). To our knowledge, the precise strategy for the thermotactic movements of either walking or flying flies has not been examined in detail (Branson et al. 2009). Tracking the detailed movements of adult fruit flies is more challenging than tracking larvae, owing to many more degrees of freedom in its basic movements (antennae, wings, and legs) in addition to the sheer speed of those movements. However, high-speed videography is becoming increasingly routine (Fry et al. 2005; Card and Dickinson 2008), and new assays for following the detailed movements of flying or walking flies (Fry et al. 2008; Branson et al. 2009) as they respond to defined thermosensory inputs may uncover the sensorimotor rules that define adult thermotactic strategy.

\section{The neural circuitry underlying thermotaxis behaviors}

A combination of genetic, behavioral, and physiological studies have demonstrated that, as in larger animals, both C. elegans and Drosophila possess thermosensory neurons and neural circuits that respond to small changes in temperature and direct appropriate behavioral responses. Below, we first describe the thermosensory neurons responsible for detecting ambient temperature changes, and then briefly discuss the known circuits that transform these sensory responses into motor output.

\section{Thermosensory neurons}

The AFD neuron pair located in the bilateral amphid sense organs of the head is a major thermosensory neuron type in C. elegans. Physical or genetic perturbation of this neuron pair severely impairs temperature-regulated navigation behaviors (Perkins et al. 1986; Mori and Ohshima 1995). In particular, such manipulations abolish isothermal tracking behavior (Mori and Ohshima 1995), indicating that the AFD neurons are the major regulators of this behavior. Disrupting AFD neuron function also weakens negative thermotaxis, although the degree of this defect remains a matter of some debate due to the use of different assay conditions, perturbation methods, and behavioral measurements in different studies (Mori and Ohshima 1995; Yamada and Ohshima 2003; Chung et al. 2006). Given the influence of parameters such as gradient steepness on thermotaxis behaviors (Yamada and Ohshima 2003; Anderson et al. 2007; Ramot et al. 2008b; Nakazato and Mochizuki 2009; Jurado et al. 2010), it is possible that the contribution of the AFD neurons to thermotaxis navigation behaviors varies under different conditions.

Distinct roles for the AFD neurons in generating either isothermal tracking or navigation behaviors could arise from altered responses of the AFD neurons to different thermal stimuli, or from altered circuit properties. Thermoresponsive properties of the AFD neurons have been investigated using genetically encoded calcium sensors and via in vivo patch-clamp recordings (Kimura et al. 2004; Biron et al. 2006; Clark et al. 2006, 2007a; Ramot et al. 2008a). These studies have shown that thermosensory responses in the AFD neurons are bidirectional and adaptive, and exhibit a broad dynamic range. Thus, these neurons respond to both warming and cooling, and can precisely track temperature oscillations of $0.003^{\circ} \mathrm{C}-0.03^{\circ} \mathrm{C} / \mathrm{sec}$, essential for the animal's ability to track isotherms and for navigation (Kimura et al. 2004; Clark et al. 2006, 2007a; Ramot et al. 2008a). Measurements of thermoreceptor currents further revealed the exquisite sensitivity of the AFD neurons, with a $\mathrm{Q}_{10}$ (reflecting the fold change in current flow over a $10^{\circ} \mathrm{C}$ rise) of $>10^{21}$ (Ramot et al. 2008a).

Remarkably, the AFD neurons modulate intracellular calcium levels only at temperatures above $T_{c}$ (Fig. 2A; Kimura et al. 2004; Clark et al. 2006), and, as in the case of thermotaxis behaviors, this threshold of response can be altered upon shifting animals to other temperatures (Kimura et al. 2004; Biron et al. 2006; Clark et al. 2006). These results suggest that the AFD neurons store the
A.

C. elegans: AFD

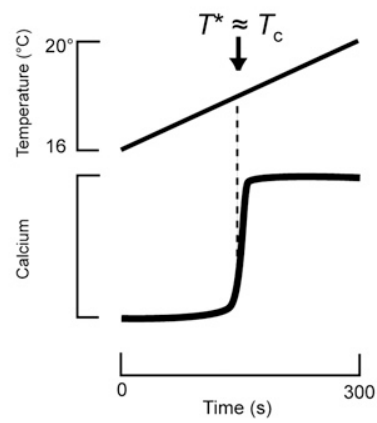

B. Drosophila: AC neurons

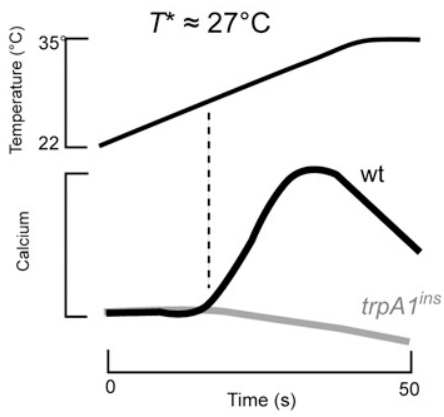

Figure 2. C. elegans and Drosophila thermoreceptor neurons are activated by warming in vivo. $(A)$ Warming above a threshold, $T^{\star}$, increases intracellular calcium in wild-type AFD neurons. $T^{\star}$ is variable and is approximately equal to the cultivation temperature, $T_{\mathrm{c}}$ (Kimura et al. 2004; Clark et al. 2006). (B) Warming above $\sim 25^{\circ} \mathrm{C}-27^{\circ} \mathrm{C}$ increases the activity of wild-type AC neurons in Drosophila. This response requires an intact trpA1 gene (gray) (Hamada et al. 2008). The experimental basis for the schemas in $A$ and $B$ is in vivo calcium imaging using genetically encoded calcium indicators. For simplicity, increases in intracellular calcium are assumed to indicate increases in cell activity. 
memory of $T_{c}$ and encode many of the thermoresponsive properties that are required for both isothermal tracking and negative thermotaxis. Such memory storage may depend on intracellular calcium buffering, since replacing the endogenous soluble calcium buffer with EGTA or BAPTA during in vivo recordings allows the threshold for AFD activation to be independent of $T_{c}$ but dependent on the holding temperature (Ramot et al. 2008a). Regardless of the mechanisms of memory storage, AFD responses do not appear to be sufficient to account for different behavioral outcomes in different temperature regimes, since calcium dynamics in the AFD neurons are similar in the temperature range at which tracking behavior is exhibited $\left(T_{c} \pm 2^{\circ} \mathrm{C}\right)$, as well as at higher temperatures that elicit negative thermotaxis in response to specific thermal stimuli (Clark et al. 2006).

Two recent studies have shown that the AWC olfactory neuron pair in the amphid organs of C. elegans also modulates thermosensory navigation behaviors (Biron et al. 2008; Kuhara et al. 2008). However, the two studies arrived at different conclusions regarding the roles of each neuron and their thermoresponsive properties, likely due to the use of different stimuli and measurement parameters. In one study, the AWC neurons were shown to respond deterministically to temperature changes above $T_{c}$, and to contribute to negative thermotaxis behavior (Kuhara et al. 2008). In the second study, the AWC neurons were found to respond in a stochastic but stimuluscorrelated manner-albeit with different temporal dynamics-to temperature changes both above and below $T_{c}$ (Biron et al. 2008). Moreover, these neurons showed higher absolute levels of activity at temperatures in the temperature range for negative thermotaxis than at temperatures at which isothermal tracking behavior is exhibited (Biron et al. 2008). This observation provides a plausible mechanism by which the circuit can distinguish the operating ranges for the two behaviors. Activity of the AWC neurons has been correlated previously with increased turning rates (Chalasani et al. 2007, 2010). Consistent with this finding, killing the AWC neurons leads to decreased turning rates on thermal gradients, resulting in weakened negative thermotaxis and enhanced isothermal tracking behavior (Biron et al. 2008). However, we note that in vivo recordings from AWC failed to detect any cooling- or warming-evoked changes in ionic current (Ramot et al. 2008a), suggesting that a resolution of the precise role of the AWC neurons in thermotaxis behaviors awaits further analysis.

Drosophila larval thermotaxis behaviors appear to be driven by thermosensory neurons activated by either high or low temperatures (Liu et al. 2003; Rosenzweig et al. 2005, 2008), and that are connected to a shared downstream circuitry to mediate negative or positive thermotaxis behaviors, respectively (Luo et al. 2010). In the larva, the terminal organ (a structure containing $\sim 30$ neurons) as well as the chordotonal neurons (a set of sensory neurons located in the larval body wall) have been implicated in regulating positive thermotaxis (Liu et al. 2003; Kwon et al. 2010). In the terminal organ, calcium imaging and extracellular recordings showed that cooling resulted in distinct alterations of the pattern of activity in different subsets of terminal organ neurons (Liu et al. 2003), suggesting that individual neuronal subsets may regulate aspects of positive thermotaxis behavior. Consistent with this hypothesis, it has been found that silencing of terminal organ neurons disrupts positive thermotaxis by affecting both the rate and direction of turning decisions in first instar larvae navigating spatial thermal gradients (Luo et al. 2010), implying that terminal organ sensory neurons regulate multiple downstream motor circuits. Larval chordotonal neurons have also been reported to respond to temperature variations (Liu et al. 2003), and, in the adult, chordotonal neurons have been implicated in temperature entrainment of the circadian clock (Sehadova et al. 2009). Consistent with involvement in positive thermotaxis, inhibiting chordotonal function has been shown to disrupt positive thermotaxis in third instar larvae (Kwon et al. 2010). Whether and how the terminal and chordotonal organs combine to regulate positive thermotaxis is not yet clear. In the adult, positive thermotaxis appears to involve cells within the third antennal segment (Hamada et al. 2008).

The sensory neurons that drive negative thermotaxis in Drosophila are not yet fully characterized. In adults, warm temperatures are sensed by a set of four AC neurons, which are located within the fly's head on the brain's anterior surface (Hamada et al. 2008). The AC neurons respond to temperatures $>25^{\circ} \mathrm{C}$, and the disruption of $\mathrm{AC}$ neuron thermoreception via mutations in the $\operatorname{trp} A 1$ channel gene (see below) causes Drosophila adults to inappropriately navigate to warmer temperatures (Fig. 2B; Hamada et al. 2008). In addition, Sayeed and Benzer (1996) reported decreased negative thermotaxis in flies whose third antennal segments were surgically removed, suggesting this appendage might also contribute to negative thermotaxis. However, Hamada et al. (2008) observed no decrement in negative thermotaxis after third antennal segment removal, complicating this picture. In the future, it will be of interest to characterize the thermosensory properties of antennal neurons and assess their effects on thermotaxis through molecular genetic manipulations.

While warmth-activated thermosensors have not been clearly defined in larvae, a set of trpA1-expressing neurons within the central brain have been implicated in negative thermotaxis (Rosenzweig et al. 2005). The expression of $\operatorname{trp} A 1$ in additional cell populations suggests that additional thermosensory neurons are present in both Drosophila larvae and adults, although some of these neurons could mediate behavioral or physiological responses distinct from thermotaxis. In particular, multidendritic neurons in the larval lateral body wall and chordotonal organ neurons also respond to temperature, making them potential candidates for modulating thermotaxis (Liu et al. 2003). But while multiple dendritic neurons mediate nociceptive responses to high-temperature stimulation (above $\sim 39^{\circ} \mathrm{C}$ ) (Tracey et al. 2003; Rosenzweig et al. 2005), their function proved dispensable for negative thermotaxis, at least when tested in the $31^{\circ} \mathrm{C}-34^{\circ} \mathrm{C}$ range (Rosenzweig et al. 2005). The possible contribution of 
chordotonal organs to negative thermotaxis is as yet unknown. Thus, as in C. elegans and mammals, multiple thermosensory neuron types in Drosophila are specialized to sense and respond to different temperature stimuli, thereby ensuring the fidelity of the behavioral response.

\section{Integration and generation of thermotactic navigation behaviors}

The circuit components required to transform thermal information into defined behavioral responses remain unclear in Drosophila. In flies, the mushroom bodies have been implicated in thermosensory behaviors (Hong et al. 2008), but their thermosensory inputs are unknown. The warm-sensitive AC neurons have been shown to project to the antennal lobe, the subesophageal ganglion, and the superior lateral protocerebrum (Hamada et al. 2008), although the roles of these regions in regulating thermosensory behaviors have not been defined.

An understanding of the circuit underlying thermosensory navigation behaviors is beginning to emerge in $C$. elegans primarily via detailed behavioral analyses in animals in which individual interneuron functions have been disrupted, and also via in vivo imaging of calcium dynamics. In particular, since the regulation of turning rates underlies thermotactic navigation behaviors (Fig. 1G; Ryu and Samuel 2002; Zariwala et al. 2003; Luo et al. 2006; Clark et al. 2007b; Ramot et al. 2008b), investigations of the neuronal circuitry promoting or inhibiting turns (Tsalik and Hobert 2003; Wakabayashi et al. 2004; Gray et al. 2005; Chalasani et al. 2007, 2010) have provided useful insight. For instance, the AIB and AIZ interneurons promote turns, whereas the AIY and AIA interneurons inhibit turns (Tsalik and Hobert 2003; Wakabayashi et al. 2004; Gray et al. 2005; Chalasani et al. 2007, 2010). These interneurons are also the major post-synaptic partners of the AFD and AWC thermosensory neurons (Fig. 3), and thus play major roles in the generation of temperature-regulated motor behaviors.

The circuit generating isothermal tracking behavior in $\mathrm{C}$. elegans The AIY interneurons respond in a $T_{c}$-dependent manner to thermal stimuli, similar to the AFD neurons (Clark et al. 2006). In addition, genetic or physical disruption of the AIY interneurons results in complete loss of isothermal tracking behavior (Mori and Ohshima 1995; Gomez et al. 2001; Murakami et al. 2005), indicating that the AFD-AIY circuit is the primary regulator of this behavior (Fig. 3A). However, increased activity of the AWC neurons disrupts isothermal tracking, and, conversely, ablation of the AWC neurons enhances tracking (Biron et al. 2008). Since isothermal tracking demands suppression of large $\Omega$ turns and reversals, a simple model suggests that increased activity of the AFD neurons and decreased activity of the AWC neurons is integrated via the post-synaptic AIY, AIA, and AIB interneurons to suppress turning rates and promote tracking (Fig. 3A). Consistent with this hypothesis, AWC neuronal activity has been shown to be low at temperatures around $T_{\mathcal{C}}$ (Biron et al. 2008), suggesting that AWC plays a permissive role in
A

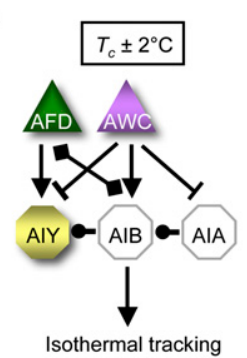

B

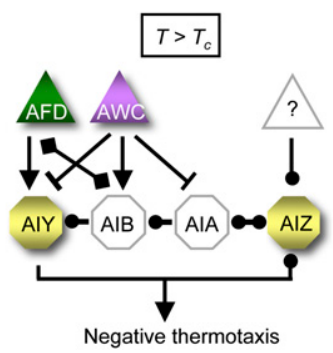

Figure 3. A working model of the circuit underlying thermotactic navigation behaviors in C. elegans. $(A, B)$ Proposed circuits regulating isothermal tracking behaviors at temperatures around $T_{c}(A)$ and negative thermotaxis at temperatures above $T_{c}(B)$. Note that the circuit generating deterministic steering during isothermal tracking remains unknown. At $T<T_{c}$, positive thermotaxis is elicited under specific conditions via mechanisms that are not fully defined. Sensory neurons and interneurons are indicated by triangles and hexagons, respectively. Neurons experimentally implicated in the indicated behaviors are indicated in color. The AIB interneurons have been suggested previously to be a component of this circuit (Mori and Ohshima 1995). Known excitatory chemical synapses are indicated by arrows, and known inhibitory synapses are indicated by bars. Lines with diamonds on each end indicate gap junctions. Lines with filled balls indicate chemical synapses of unknown sign. See the text for additional details and references.

isothermal tracking behavior. Neither the sensorimotor transformation responsible for isothermal alignment during isothermal tracking nor the neural circuits that produce deterministic steering are currently known.

The circuit generating negative thermotaxis in C. elegans The regulation of negative thermotaxis behavior is more complex (Fig. 3B). Loss of AIY function results in constitutive negative thermotaxis behavior (Mori and Ohshima 1995; Hobert et al. 1997; Chung et al. 2006), indicating that the AIY neurons inhibit negative thermotaxis behavior at $T<T_{c}$. Since, in the absence of AIY function, animals retain the ability to discriminate temperature differences and move down the gradient, an alternate circuit must also mediate negative thermotaxis. The AIZ interneurons may be major contributors to this behavior, since ablation of the AIZ interneurons abolishes negative thermotaxis at $T>T_{c}$ (Mori and Ohshima 1995; Chung et al. 2006). Consistent with this role, the AIZ neurons respond to rising temperatures above $T_{c}$ as revealed via calcium imaging experiments (Kodama et al. 2006; Kuhara and Mori 2006). However, it is unclear whether the AIZ interneurons are directly temperature responsive, or whether these neurons are post-synaptic to an as-yet-unidentified thermosensory neuron type (Fig. 3B).

A working model based on current observations suggests that, at $T>T_{c}$, rising temperatures increase the activity of the AFD and AWC neurons, and possibly an additional thermosensory neuron type(s) that is presynaptic to the AIZ interneurons. Integration of thermal information by the downstream network of AIY, AIA, $\mathrm{AIB}$, and AIZ interneurons results in an increased turn 
probability when moving up the gradient. Conversely, when temperatures are falling, decreased activity of the thermosensory neurons results in a decreased turn probability, leading to a net migration of animals down the gradient. At $T<T_{c}$, loss of the AIY interneurons may result in negative thermotaxis, perhaps via modulation of AIZ activity. Under certain conditions, this circuit may also promote positive thermotaxis (Hedgecock and Russell 1975; Mori and Ohshima 1995; Ramot et al. 2008b; Jurado et al. 2010). It is important to note that, given the precision of the exhibited behaviors and their dependence on environmental conditions and past experience, additional sensory as well as interneurons are likely to be recruited into the circuit under defined external and internal conditions.

\section{Molecules and mechanisms of thermosensitivity}

Our working model is that extraordinary temperature dependence is conferred by molecules specifically expressed in thermosensory neurons. The best-studied thermoreceptor molecules are members of the TRP family of cation channels, which have been implicated in thermosensation in both vertebrates and Drosophila (for recent reviews, see Dhaka et al. 2006; Damann et al. 2008). However, thermosensation may be mediated by additional mechanisms in C. elegans.

\section{Genetic approaches for the identification} of thermosensitive molecules

Screens for genes required for thermosensation and avoidance of noxious temperature have been conducted only recently (Tracey et al. 2003; Lee et al. 2005; Mohri et al. 2005; Okochi et al. 2005; Hong et al. 2006). To our knowledge, no such screens have been attempted in mice, although it is known that inbred mouse strains differ in their preferred temperature (Leon 2005). A significant challenge associated with this approach is that most, if not all, behavioral assays for thermosensation rely on the responses of populations of animals to thermal gradients. Such population-based assays complicate screening, gene mapping, and cloning, limiting the usefulness of forward genetic screens for identifying new genes required for extraordinary thermosensitivity. However, recent advances in sequencing technologies bypass the need for fine mapping, and may facilitate the identification of genes via forward genetic screens (Sarin et al. 2008; Shen et al. 2008).

The first genetic studies of thermosensation in $C$. elegans used mutants defective in chemotaxis (Dusenbery et al. 1975) as a starting point, defining a small group of genes required for normal thermotaxis as well as chemotaxis (for review, see Mori 1999). Such genes (Table 1) encode ion channels, kinases, phosphatases, and other signaling molecules, as well as transcription factors needed for the specification and development of the AFD thermosensory neurons and the AIY interneurons. Unexpectedly, none of these genes encode TRP channels. This is not due to a lack of TRP channels in worms, however, since phylogenetic analyses using sequences encoding the predicted TM4-TM6 pore-containing region of TRP channels indicates that the C. elegans genome is predicted to encode at least 24 TRP channels, including relatives of insect and mammalian temperature-sensitive TRPs (Goodman and Schwarz 2003; P Garrity, unpubl.). Nor is it due to a lack of temperature-sensitivity in $C$. elegans TRP channels generally, since a worm relative of TRPA1 forms cold-activated channels in heterologous cells and is required for cold-evoked increases in the

Table 1. A subset of genes required for C. elegans thermotaxis

\begin{tabular}{|c|c|c|c|c|}
\hline Gene & Concise description & NCBI KOG & Cells expressed & References \\
\hline $\operatorname{tax}-4$ & $\begin{array}{l}\alpha \text { Subunit of } \\
\text { cGMP-gated } \\
\text { ion channel } \\
\quad \text { http:// }\end{array}$ & $\begin{array}{l}\text { Cyclic nucleotide-gated } \\
\text { cation channel [KOG0500] } \\
\text { rrmbase.org/db/gene/gene?nam }\end{array}$ & $\begin{array}{l}\text { AFD, AWC, ASE, ASG, ASK, } \\
\text { ASI, ASJ, BAG, and URX } \\
\text { WBGene00006526; class=Gene }\end{array}$ & $\begin{array}{c}\text { Komatsu et al. } \\
1996,1999\end{array}$ \\
\hline $\operatorname{tax}-2$ & $\begin{array}{l}\beta \text { Subunit of } \\
\text { cGMP-gated } \\
\text { ion channel } \\
\\
\text { http:// }\end{array}$ & $\begin{array}{l}\text { Cyclic nucleotide-gated } \\
\text { cation channel [KOG0499] } \\
\text { prmbase.org/db/gene/gene?nam }\end{array}$ & $\begin{array}{l}\text { Same as for } \operatorname{tax}-4 \\
\text { WBGene } 00006525 \text {; class=Gene }\end{array}$ & $\begin{array}{l}\text { Coburn and Bargmann } \\
\text { 1996; Komatsu } \\
\text { et al. } 1999\end{array}$ \\
\hline $\operatorname{tax}-6$ & Calcineurin A & $\begin{array}{l}\text { Serine-threonine } \\
\text { phosphatase 2B, catalytic } \\
\text { subunit [KOG0375] } \\
\text { prmbase.org/db/gene/gene?nam }\end{array}$ & $\begin{array}{l}\text { Sensory neurons (including AFD } \\
\text { and AWC); interneurons; } \\
\text { motor neurons } \\
\text { WBGene00006527; class=Gene }\end{array}$ & Kuhara et al. 2002 \\
\hline$t t x-4 / p k c-1$ & $\begin{array}{l}\text { Protein kinase } C \varepsilon \\
\qquad \text { http:// }\end{array}$ & $\begin{array}{l}\text { Serine/threonine } \\
\text { protein kinase } \\
\text { [KOG0694] } \\
\text { prmbase.org/db/gene/gene?nam }\end{array}$ & $\begin{array}{l}\text { Sensory neurons (including AFD } \\
\text { and AWC); interneurons; } \\
\text { motor neurons } \\
\text { WBGene00004032; class=Gene }\end{array}$ & Okochi et al. 2005 \\
\hline$t t x-1$ & $\begin{array}{l}\text { OTD/OTX subclass } \\
\text { of homeodomain } \\
\text { transcription } \\
\text { factors http:// }\end{array}$ & $\begin{array}{l}\text { Homeobox transcription } \\
\text { factor [KOG2251] }\end{array}$ & $\begin{array}{l}\text { AFD + additional nonneuronal } \\
\text { cells }\end{array}$ & $\begin{array}{l}\text { Hedgecock and } \\
\text { Russell 1975; } \\
\text { Satterlee et al. } 2001\end{array}$ \\
\hline
\end{tabular}


nociceptive PVD neurons in vivo /Chatzigeorgiou et al. 2010).

Additional genes required for thermosensation have been discovered using candidate gene approaches as well as cell-specific gene expression profiling of embryonic neurons in C. elegans. Two studies sought to identify AFD-specific genes using either an olfactory (AWB) or gustatory (ASE) neuron as a reference (Colosimo et al. 2004; Etchberger et al. 2007). Twenty-four genes were upregulated in AFD with respect to the reference neuron in both studies, including four previously identified AFDexpressed genes. The 20 novel genes include a phosphodiesterase (pde-5), a transcription factor (dac-1), a G protein-coupled receptor or GPCR (srtx-1), a heat-shock protein (hsp-16.49), and a nuclear hormone receptor (nhr-268) gene. Defects in the srtx-1 gene, which is expressed in AFD and AWC, disrupt isothermal tracking by hyperactivating the AWC neurons (Biron et al. 2008), whereas dac-1 acts in the AFD neurons to regulate negative thermotaxis (Colosimo et al. 2004).

In flies, forward and reverse genetics in Drosophila have highlighted genes that contribute to thermal information processing in both larvae and adult flies. These genes include a suite of TRP channel genes: painless (Tracey et al. 2003), trpA1 (Rosenzweig et al. 2005; Hamada et al. 2008), and pyrexia (Table 2; Lee et al. 2005). Below, we discuss what is understood about how each of these channels contributes to thermosensation. Additional molecules identified using genetic tools include receptors for histamine and enzymes required for histamine synthesis (Hong et al. 2006), phospholipase C signaling pathway components (Kwon et al. 2008), and cAMP signaling pathway genes previously known for their role in memory formation (Hong et al. 2008).

\section{Thermosensor proteins and networks}

In vertebrates, temperature sensation depends on ion channels of the TRP family activated by warming or cooling (Dhaka et al. 2006; Damann et al. 2008). This role for TRP channels may be conserved in Drosophila and
C. elegans, particularly with respect to the detection of noxious thermal stimuli. Painless was the first invertebrate TRP channel shown to be required for thermal sensation. Specifically, Painless is essential for the ability of Drosophila larvae to avoid noxious thermal stimuli (Tracey et al. 2003; Xu et al. 2006). Consistent with the idea that Painless acts as a molecular thermosensor in Drosophila, it forms ion channels activated by warming to $>40^{\circ} \mathrm{C}$ in heterologous cells (Sokabe et al. 2008). In $C$. elegans, acute exposure to cold induces an avoidance response that requires an intact trpa-1 gene /Chatzigeorgiou et al. 2010). Expressing the C. elegans TRPA-1 protein in heterologous cells produces a cold-sensitive, nonselective ion current (Chatzigeorgiou et al. 2010).

Direct temperature regulation of ion channels is not the only way to achieve extraordinary temperature dependence, however. In C. elegans, the AFD neurons use a cGMP-dependent molecular network to regulate an ion channel (Box 1). In this network, temperature regulates the concentration of cGMP in the cytoplasm, which then determines the fraction of cGMP-gated ion channels open at a given temperature. This model is supported by in vivo whole-cell patch-clamp recordings of the AFD neurons (Ramot et al. 2008a). The ion channel regulated by temperature in AFD is formed by the TAX-4 and TAX-2 cyclic nucleotide-gated channel proteins (Coburn and Bargmann 1996; Komatsu et al. 1996). Both subunits are required, since a defect in either the $\operatorname{tax}-4$ or $\operatorname{tax}-2$ gene is sufficient to abolish the extraordinary thermosensitivity of the AFD neurons. This agrees with the observation that both proteins are required to form a channel with high affinity for cGMP in heterologous cells (Komatsu et al. 1999). Thermoreceptor currents in AFD also depend on three receptor guanylate cyclases (rGCs) (Ramot et al. 2008a). Consistent with their central role in temperaturedependent regulation of the TAX-4/2 ion channel, all three rGCs (GCY-8, GCY-18, and GCY-23) are expressed exclusively by the AFD neurons (Inada et al. 2006). The PDE that operates in this network is not yet known. Importantly, how temperature regulates this signaling pathway remains to be established.

Table 2. TRP channels that serve as thermosensors in Drosophila

\begin{tabular}{|c|c|c|c|c|}
\hline Channel & $T_{\text {threshold }}{ }^{\mathrm{a}}$ & $Q_{10}{ }^{\mathrm{a}}$ & Tissues expressed & References \\
\hline TRPA1 & $24^{\circ} \mathrm{C}-29^{\circ} \mathrm{C}$ & n.d. & $\begin{array}{l}\text { Adult flies: LC, VC, and AC neurons, } \\
\text { Labral sense organ; Larvae: Unknown }\end{array}$ & $\begin{array}{l}\text { Viswanath et al. } 2003 \text {; } \\
\text { Hamada et al. } 2008\end{array}$ \\
\hline CeTRPA-1 & $\begin{array}{l}\text { Activated by } \\
\text { cooling }\end{array}$ & n.d. & Adult worms: PVD sensory neurons & Chatzigeorgiou et al. 2010 \\
\hline Painless & $44^{\circ} \mathrm{C}^{\mathrm{c}}$ & 28.5 & $\begin{array}{l}\text { Adult flies: gustatory sensory neurons } \\
\text { (proboscis, legs, and wings), Johnson's } \\
\text { organ; Larvae: multidendritic neurons, } \\
\text { chordotonal organs }\end{array}$ & $\begin{array}{l}\text { Tracey et al. 2003; Xu et al. 2006; } \\
\text { Sokabe et al. } 2008\end{array}$ \\
\hline PyxA & $40^{\circ} \mathrm{C}$ & 18 & $\begin{array}{l}\text { Adult flies: antennae, bristles, proboscis } \\
\text { sensory neurons; Larvae: multidendritic } \\
\text { neurons, others. }\end{array}$ & Lee et al. 2005 \\
\hline РyxB & $38^{\circ} \mathrm{C}$ & 15 & Not known if different from PyxA & Lee et al. 2005 \\
\hline
\end{tabular}

(n.d.) Not determined.

${ }^{a}$ Determined using voltage-clamp recording of heterologously expressed channels.

${ }^{\mathrm{b}}$ CeTRPA-1 is activated by cooling from room temperature, but the threshold for activation has yet to be measured.

${ }^{\mathrm{c}} \mathrm{With}\left[\mathrm{Ca}^{2+}\right]_{\text {out }}=2 \mathrm{mM}$; no $\mathrm{Ca}^{2+}$ added to the recording solution. 
Box 1. A molecular network for temperature sensing by AFD.

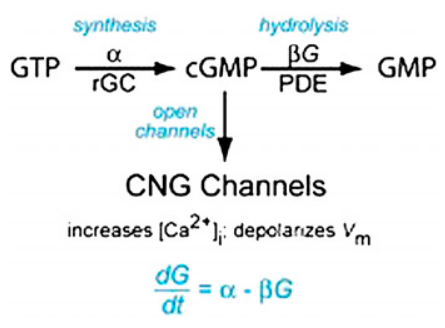

In this model, $G$, the intramicrovillar cGMP concentration, decreases in response to cooling and increases in response to warming (above threshold). (rGC) Receptor-type guanylate cyclase; $(\alpha)$ rate of synthesis; (PDE) cGMP phosphodiesterase; $(\beta)$ hydrolysis rate.

This molecular network may be shared by the lightsensitive ASJ neurons in C. elegans. Recent work suggests that this network operates as follows: Light activates the LITE-1 GPCR, which acts via a G protein to increase the activity of an $\mathrm{rGC}$, increasing intracellular cGMP levels and activating TAX-4/2 channels (Ward et al. 2008; Liu et al. 2010). This differs from cGMP-dependent phototransduction in vertebrates, in which the activity of PDEs but not rGCs is light-dependent (Fu and Yau 2007). It will be interesting to learn whether the proposed temperaturedependent regulation of cGMP concentration in the AFD neurons arises from direct effects of temperature on rGCs or PDE(s), or indirect modulation of one or both enzymes.

Temperature responses in the AFD neurons resemble light responses in ciliary photoreceptors such as those that mediate vision in mammals (Yau and Hardie 2009). Vertebrate photoreceptors and worm AFD neurons signal the presence of stimuli by modulating the activity of a cGMPgated ion channel, and use nonlinear amplification to enhance sensitivity and adaptation to maintain sensitivity to a wide range of stimulus values. Thermoreceptor currents are the result of a nonlinear amplification mechanism that remains to be elucidated (Ramot et al. 2008a). Adaptation to ambient temperature enables the AFD to retain such sensitivity across the entire physiological temperature range $\left(15^{\circ} \mathrm{C}-25^{\circ} \mathrm{C}\right)$.

Less is known about the molecular networks activated by warming in the AWC neurons. Like AFD, AWC relies on the tax-4 channel gene (Kuhara et al. 2008). Such responses are impaired in mutants lacking ODR-3 G $\alpha$ and enhanced in animals with defects in the eat-16 RGS (regulator of G protein signaling) gene (Kuhara et al. 2008), suggesting that AWC uses G protein-mediated cGMP signaling for thermosensation. Thus, the proposed model for thermosensory transduction by the AWC neurons mirrors the better-understood network required for chemosensory transduction (Bargmann 2006). However, as mentioned above, the thermoresponsive properties of the AWC neurons require additional investigation.

The best-characterized molecular thermosensors are TRP channels directly regulated by temperature. The $D$. melanogaster genome has 16 genes predicted to encode TRP channels, at least six of which (inactive, trp, trpl, $\operatorname{trp} A 1$, pyrexia, and painless) have been implicated in thermotaxis or responses to noxious heat (Table 2). Three (TRPA1, Pyrexia, and Painless) are activated by warming when expressed in heterologous cells, suggesting they serve as molecular sensors of warming. TRPA 1 is activated by moderately warm temperatures $\left(25^{\circ} \mathrm{C}-27^{\circ} \mathrm{C}\right)$ (Viswanath et al. 2003; Hamada et al. 2008), consistent with its role in thermotaxis (Rosenzweig et al. 2005; Hamada et al. 2008; Kwon et al. 2008), while Pyrexia and Painless have thresholds of $\sim 37^{\circ} \mathrm{C}$ and $42^{\circ} \mathrm{C}$ (Lee et al. 2005; Sokabe et al. 2008), consistent with their roles in behavioral responses to temperatures in this higher range (Tracey et al. 2003; Lee et al. 2005). In contrast, the molecular sensors Drosophila use to detect lower temperatures are unknown. Three TRP channel genes (trpl, trp, and inactive) are candidates for encoding such low-temperature detectors, as mutations in these genes disrupt positive thermotaxis (Rosenzweig et al. 2008; Kwon et al. 2010). trpl and trpl encode closely related channels with overlapping roles in phototransduction (Hardie and Minke 1992; Niemeyer et al. 1996). For positive thermotaxis, trpl appears more important than trp, as trpl mutant defects are stronger and have been observed in both first and third instar larvae, while trp mutant defects have been observed only in first instar larvae and not in all trp mutant backgrounds (Rosenzweig et al. 2008; Kwon et al. 2010). Despite the promising genetic data, direct cold activation of TRPL, TRP, or Inactive currents remains to be demonstrated, and these channels could mediate positive thermotaxis without serving as molecular temperature sensors. Precedent for indirect activation of TRP and TRPL comes from studies of Drosophila phototransduction, where photon absorption initiates a signaling cascade that promotes TRP and TRPL channel opening via the phospolipase C NorpA (Bloomquist et al. 1988; Hardie and Minke 1992; McKay et al. 1995; Niemeyer et al. 1996). This specific pathway is not responsible for regulating low-temperature responses, however, as norpA mutants show no defects in positive thermotaxis (Rosenzweig et al. 2008).

It is worth noting that not only TRP and TRPL, but all of the Drosophila TRPs implicated in thermosensory behavior participate in detecting other sensory stimuli, including sugar (Xu et al. 2008), gravity (Sun et al. 2009), and reactive chemicals (Kang et al. 2010). The specific stimuli that activate a given TRP channel can depend on cellular context, as in the activation of TRP and TRPL by light via the phototransduction cascade (Bloomquist et al. 1988; Hardie and Minke 1992; McKay et al. 1995; Niemeyer et al. 1996). In other cases, expression of a single TRP channel appears sufficient to confer responsiveness to multiple stimuli across a wide range of cell types, as in the activation of TRPA1 by temperature and chemicals (Kang et al. 2010). The apparently intrinsic temperature sensitivity of TRPA1 and PAINLESS and the low thermal mass of Drosophila implies that many cells expressing these proteins will be highly temperaturesensitive. This opens the possibility for thermosensation 
to be integrated with other modalities within primary sensory neurons.

\section{Neurotransmitters}

How is thermal information transmitted from specialized thermosensory neurons in C. elegans? Based on the expression of the eat-4 vesicular glutamate transporter (Lee et al. 1999), both the AFD and AWC neurons likely use glutamate as a neurotransmitter. In support of this idea, the post-synaptic interneuron partners of AFD and AWC express ionotropic glutamate receptors (Hart et al. 1995; Maricq et al. 1995; Wenick and Hobert 2004). Inhibition of the AIY interneurons by AWC is accomplished via activation of the GLC-3 glutamate-activated chloride channel (Chalasani et al. 2007). However, since the AFD-AIY synapse is likely excitatory (Clark et al. 2006), a distinct receptor may be involved. The ability of AFD to excite AIY and the ability of AWC to inhibit AIY suggest that these synapses are spatially and electrically isolated from one another. The AIB and AIA interneurons also receive glutamatergic input from AWC. The AIB neurons express the GLR-1 glutamate-activated cation channel and are excited by AWC (Chalasani et al. 2007), while the AIA neurons express GLC-3 and are inhibited by AWC (Chalasani et al. 2010). Intriguingly, AWC engages the AIB and AIA neurons in a common, dyadic synapse (White et al. 1986), implying that AWC modulates these interneurons in a coordinated, reciprocal fashion.

Consistent with the idea that the AFD and AWC thermosensory neurons require glutamate to transmit thermal information, eat-4 mutants show defects in thermotaxis (Yamada and Ohshima 2003). Both neurons also express genes predicted to encode neuropeptides (Li et al. 1999; Nathoo et al. 2001), although the role of neuropeptides in either the acute or chronic response to temperature is unknown. Thermal information processing in Drosophila relies on histamine as a neurotransmitter, but the specific neuronal populations involved have not been identified (Hong et al. 2006). Thus, there are multiple regions of the CNS that engage in temperature sensation and thermal information processing. It will be interesting to learn how these pathways interact to regulate thermotaxis, avoidance of noxious heat, and temperature-compensated circadian clocks in Drosophila.

\section{Plasticity in C. elegans thermotaxis behaviors}

Two environmental factors have strong effects on $C$. elegans thermotaxis: bacterial food and cultivation temperature. The response of starved worms to thermal gradients is debated, with some research groups reporting that the ability of starved worms to perform negative thermotaxis is decreased while isothermal tracking behavior is unaffected (Biron et al. 2006; Chi et al. 2007; Ramot et al. 2008b), and others reporting that starvation causes worms to avoid their cultivation temperature (Hedgecock and Russell 1975; Mohri et al. 2005). Regardless of the impact of starvation, the information regarding feeding state is not carried by the AFD sensory neurons (Biron et al. 2006; Kodama et al. 2006; Ramot et al. 2008a).
In contrast, the response of the AIZ interneurons to temperature is decreased by starvation (Kodama et al. 2006; Kuhara and Mori 2006), and may contribute to the weakened negative thermotaxis behavior (Chi et al. 2007; Ramot et al. 2008b). Defects in the ins-1 insulin-related peptide and the tax- 6 calcineurin gene impair behavioral responses to food deprivation as well as starvationdependent inhibition of warming-evoked calcium signals in the AIZ interneurons (Kodama et al. 2006; Kuhara and Mori 2006). Genetic analyses indicate that, in starved animals, INS-1 production by unidentified neurons inhibits insulin signaling by antagonizing the DAF-2 insulin receptor and the AGE-1 phosphotidylinositol 3 kinase (Kodama et al. 2006). Analysis of the site of action of age-1 and tax- 6 suggests that, in addition to the AIZ interneurons, starvation-mediated plasticity may involve the AIY and RIA interneurons (Kodama et al. 2006; Kuhara and Mori 2006). It is interesting to note that AWC neuronal activity has been shown recently to be modulated by insulin signaling from the downstream AIA interneurons (Chalasani et al. 2010), suggesting that the AWC neurons may also represent a locus of integration of food and temperature cues.

As described above, shifting worms to a new cultivation temperature causes a shift in thermal preference over a matter of hours (Hedgecock and Russell 1975; Mohri et al. 2005; Kodama et al. 2006; Kuhara and Mori 2006). Both well-fed and starved animals exhibit plasticity in their thermal preference, establishing a new value $\sim 2 \mathrm{~h}$ following a temperature shift (Biron et al. 2006; Chi et al. 2007; Ramot et al. 2008a). The intracellular calciumdependent memory of $T_{c}$ appears to be stored in the AFD thermosensory neurons (Kimura et al. 2004; Biron et al. 2006), although temporal dynamics of AWC neuronal activity are also modulated by $T_{c}$ (Biron et al. 2006; Kuhara et al. 2008). Mutations in the $d g k-3$ diacylglycerol kinase significantly affect the rate at which worms adapt to (learn) a new cultivation temperature by modulating the rate of resetting of the threshold of AFD output to the AIY interneurons, but have no effect on the rate at which the threshold for warming-evoked changes in intracellular calcium in AFD is altered (Biron et al. 2006). A key advance will be the discovery of the molecular and cellular mechanisms essential for plasticity in $T_{c}$ in $C$. elegans thermosensory neurons.

\section{Thermosensory regulation of development}

In addition to regulating navigation behaviors, do the identified thermosensory circuits actively modulate other temperature-dependent processes? To compensate for the intrinsic temperature dependence of all biochemical reactions, animals have evolved mechanisms by which the rates of specific biological processes, such as circadian rhythms, are kept constant across a broad temperature range (Pittendrigh 1954; Hastings and Sweeney 1957). However, other phenotypes-such as rates of locomotion, metabolism, and life span-are significantly affected by ambient temperature (Shaw and Bercaw 1962; Klass 1977; Dusenbery and Barr 1980; Hosono et al. 1982; 
Bennett 1990; Vermeulen and Bijlsma 2004; Galbadage and Hartman 2008). This could simply be a result of systemic temperature effects, or due to active modulation by inputs from dedicated thermosensory pathways. In mice, reduction of core body temperature via genetic manipulation of hypothalamic neurons results in increased life span, suggesting that longevity is under active temperature control (Conti et al. 2006). Work in C. elegans suggests that many developmental processes are similarly under active modulation by thermosensory inputs, and that temperature is sensed and integrated together with other external and internal cues to regulate these pathways.

A well-studied temperature-dependent developmental process in C. elegans is the decision of larvae to enter into, or exit from, the stress-resistant dauer developmental stage (Golden and Riddle 1984a,b). The primary trigger regulating dauer entry is the concentration of dauer pheromone, a complex mix of fatty acid-linked ascaroside sugar derivatives (Golden and Riddle 1982, 1984b; Jeong et al. 2005; Butcher et al. 2007, 2008, 2009; Pungaliya et al. 2009|. Pheromone-induced dauer formation is temperature-dependent, such that, at a given pheromone concentration, more larvae enter into the dauer stage at higher temperatures (Golden and Riddle 1984a; Ailion and Thomas 2000). The composition profile of dauer pheromone is also distinct at different temperatures (Butcher et al. 2008). Genetically disrupting AFD neuron function via the ttx-1 mutation results in hypersensitivity to pheromone and promotes dauer recovery at lower temperatures (Golden and Riddle 1984a; Ailion and Thomas 2000; Satterlee et al. 2001), suggesting that the AFD neurons modulate the temperature regulation of the pathway. However, the temperature dependence of dauer formation by pheromone is retained (Golden and Riddle 1984a; Ailion and Thomas 2000), indicating that neurons other than AFD must also mediate temperature input. The existence of multiple temperature-responsive pathways is also supported by observations that high temperatures of $27^{\circ} \mathrm{C}$ are sufficient to promote dauer entry in a pheromone-independent manner, and that this process is unaffected in ttx-1 mutants (Ailion and Thomas 2000). It will be interesting to determine whether other thermosensitive neurons, such as the AWC neurons (Biron et al. 2008; Kuhara et al. 2008), also play a role in the temperature-dependent regulation of dauer formation.

Hints of the mechanisms by which thermosensory inputs coordinate organism-wide responses came from investigations into the thermal regulation of aging. As in other ectotherms, the life span of C. elegans is shorter at higher temperatures (Klass 1977). Perturbation of AFD function results in an even shorter life span at higher temperatures of $25^{\circ} \mathrm{C}$, although life span at lower temperatures is unaffected (Lee and Kenyon 2009), suggesting that AFD contributes to the temperature dependence of life span. This regulation appears to be effected via modulation of neuroendocrine signaling and regulation of expression of the daf-9 cytochrome P450 gene (Lee and Kenyon 2009). DAF-9 regulates the production of the bile acid-like dafachronic acid steroids, which act as ligands for the DAF-12 nuclear hormone receptor (Antebi et al.
2000; Motola et al. 2006). Reduction-of-function mutations in daf-9 decrease longevity at higher temperatures (Gerisch et al. 2001). daf-9 expression is decreased in $t t x-1$ mutants at $25^{\circ} \mathrm{C}$, and the shortened life span of $t t x-1$ mutants can be suppressed by increased expression of daf- 9 in neuroendocrine cells, as well as by loss of daf-12 function (Lee and Kenyon 2009). A model consistent with these observations is that, for $T_{c}>25^{\circ} \mathrm{C}$, AFD-mediated thermosensory inputs increase daf-9 expression and regulate longevity via DAF-12. Interestingly, DAF-9-produced dafachronic acids are also the major downstream mediators of dauer formation via DAF-12 (Gerisch et al. 2001; Jia et al. 2002; Gerisch and Antebi 2004; Mak and Ruvkun 2004). As in the case of longevity, absence of AFD may result in inappropriate daf-9 expression at a given temperature, resulting in pheromone hypersensitivity in dauer formation. Thus, hormonal signaling from the AFD and other thermosensory neurons may organize a genome-wide developmental response in response to environmental temperature (see also Tissenbaum et al. 2000). However, similar to dauer formation, longevity remains temperature-sensitive in animals lacking AFD function, further underscoring the existence of multiple temperature-sensing neurons.

A particularly unexpected finding was the requirement for the AFD neurons in regulating heat-shock responses in C. elegans, a response generally considered to be cellautonomous. Upon heat shock, organism-wide levels of hsp mRNAs are dramatically decreased in animals in which AFD neuron functions were compromised via either physical or genetic perturbations (Prahlad et al. 2008). Moreover, these animals were found to be less tolerant to thermal stress (Prahlad et al. 2008). Taken together, these observations suggest that, in addition to regulating behavioral decisions, thermosensory neurons act in a cell-nonautonomous manner to regulate the temperature dependence of multiple developmental processes in C. elegans.

\section{Conclusions and perspectives}

A theme emerging from this overview is that the study of thermotaxis in C. elegans and D. melanogaster is amenable to analysis at many different levels of inquiry, from the molecular to the small circuit to the systems levels. The ability to synthesize observations made across these levels provides a unique opportunity to gain detailed insights into how molecules and circuits shape complex behaviors. In this way, the study of thermotaxis in these model organisms provides an experimental and theoretical platform to investigate questions at the forefront of modern neuroscience, not only in these model systems, but also in more complex animals like humans. How are complex behaviors generated from the activities of neural circuits? How do behaviors differ among individuals and between species, and what are the critical underlying molecular and cellular differences that contribute to these differences? Studies of a readily quantifiable behavior such as thermotaxis in C. elegans and $D$. melanogaster have the potential to provide rapid insights into the answers to these questions. 
However, many key issues remain to be resolved. In C. elegans, a major open question is the molecular nature of the temperature sensor(s). While a cGMP-dependent signaling pathway is required for thermal activation of the AFD neurons, the molecular thermosensor remains unknown. Identification of this thermosensor is important not only for understanding the molecular principles that govern the exceptional thermal sensitivity of the AFD neuron, but also for determining the molecular mechanisms that reset the AFD threshold in response to cultivation temperature. Similarly, the molecular sensor of cool temperature in D. melanogaster is uncertain. At the level of the neural circuit, very little is known about the neural circuits involved in temperature detection in Drosophila: The larval warm sensors and the adult cold sensors are defined with low resolution, and the circuits that control thermosensory behavior downstream from the sensors in larvae and adults are largely unknown. The further definition of these circuits in both roundworms and flies will provide additional opportunities to monitor and manipulate their functions in vivo. In particular, we anticipate that cell type-specific molecular genetic alterations and inducible manipulations of neuronal activity (e.g., see Zhang et al. 2007) will increasingly be coupled with high-resolution tracking of thermotactic behavior in both C. elegans and D. melanogaster. This powerful combination will greatly advance our understanding of the molecular and neuronal networks that generate defined behavioral outputs.

Finally, recent advances in genomics provide the opportunity to extend the study of thermotaxis beyond the confines of traditional model systems, and to pursue comprehensive intra- and interspecies behavioral analyses. The potential richness of the vast natural reservoir of behavioral and genetic variation is suggested by work demonstrating differences in the thermotactic behavior of two independent isolates of C. elegans: the N2 and CB4856 strains (Anderson et al. 2007). While the thermal preference of the standard laboratory N2 strain is highly plastic, CB4856 shows a much more rigid preference and is analogous to fruit flies in this respect (Anderson et al. 2007). The underlying molecular and circuit basis of this difference is unknown, but this observation hints at how studying natural variation in thermotaxis can provide the framework for a broader view of thermotaxis. In addition, it underlines how our current view of the molecular genetics of behavior is influenced by the characteristics-and, potentially, the idiosyncrasies-of the small populations of animals selected for study in the laboratory decades ago. Our current knowledge of the molecular genetics of thermotaxis in these organisms is almost entirely based on experiments on a few specific laboratory strains. Fortunately, advances in molecular genetics and genomics now open up the possibility of exploring both intra- and interspecies variation, an area that is likely to be an important driving force of discovery in the near future. Given the increasingly detailed mechanistic understanding of thermotactic behavior, thermotaxis should prove a useful model for the effort to link variation in a complex behavioral trait to un- derlying evolutionary changes at the molecular and circuit level.

\section{Acknowledgments}

We acknowledge contributions from members of our laboratories. Related work in our laboratories is supported by NIH grants PO1 NS044232 (to P.G.), R21 NS061147 (to M.B.G.), DP1 OD004064 (to A.D.S.), and RO1 GM081639 (to P.S.), and NSF grants 0725079 (to M.B.G.) and 1025307 (to P.G.).

\section{References}

Ailion M, Thomas JH. 2000. Dauer formation induced by high temperatures in Caenorhabditis elegans. Genetics 156: 1047-1067.

Ainsley JA, Kim MJ, Wegman LJ, Pettus JM, Johnson WA. 2008. Sensory mechanisms controlling the timing of larval developmental and behavioral transitions require the Drosophila DEG/ENaC subunit, Pickpocket1. Dev Biol 322: 46-55.

Anderson JL, Albergotti L, Proulx S, Peden C, Huey RB, Phillips PC. 2007. Thermal preference of Caenorhabditis elegans: A null model and empirical tests. J Exp Biol 210: 3107-3116.

Antebi A, Yeh WH, Tait D, Hedgecock EM, Riddle DL. 2000. daf-12 encodes a nuclear receptor that regulates the dauer diapause and developmental age in C. elegans. Genes Dev 14: $1512-1527$.

Bargmann CI. 2006. Chemosensation in C. elegans. In WormBook (ed. The C. elegans Research Community). WormBook. doi: 10.1895/wormbook.1.123.1. http://www.wormbook.org.

Bennett AF. 1990. Thermal dependence of locomotor capacity. Am J Physiol 259: R253-R258.

Biron D, Shibuya M, Gabel C, Wasserman SM, Clark DA, Brown A, Sengupta P, Samuel AD. 2006. A diacylglycerol kinase modulates long-term thermotactic behavioral plasticity in $C$. elegans. Nat Neurosci 9: 1499-1505.

Biron D, Wasserman SM, Thomas JH, Samuel AD, Sengupta P. 2008. An olfactory neuron responds stochastically to temperature and modulates $C$. elegans thermotactic behavior. Proc Natl Acad Sci 105: 11002-11007.

Bloomquist BT, Shortridge RD, Schneuwly S, Perdew M, Montell C, Steller H, Rubin G, Pak WL. 1988. Isolation of a putative phospholipase C gene of Drosophila, norpA, and its role in phototransduction. Cell 54: 723-733.

Branson K, Robie AA, Bender J, Perona P, Dickinson MH. 2009. High-throughput ethomics in large groups of Drosophila. Nat Methods 6: 451-457.

Bullock TH, Diecke FP. 1956. Properties of an infra-red receptor. I Physiol 134: 47-87.

Butcher RA, Fujita M, Schroeder FC, Clardy J. 2007. Small molecule signaling of dauer formation in C. elegans. Nat Chem Biol 3: 420-422.

Butcher RA, Ragains JR, Kim E, Clardy J. 2008. A potent dauer pheromone component in Caenorhabditis elegans that acts synergistically with other components. Proc Natl Acad Sci 105: 14288-14292.

Butcher RA, Ragains JR, Clardy J. 2009. An indole-containing dauer pheromone component with unusual dauer inhibitory activity at higher concentrations. Org Lett 11: 3100-3103.

Card G, Dickinson MH. 2008. Visually mediated motor planning in the escape response of Drosophila. Curr Biol 18: 1300-1307.

Chalasani SH, Chronis N, Tsunozaki M, Gray JM, Ramot D, Goodman MB, Bargmann CI. 2007. Dissecting a neural circuit for food-seeking behavior in Caenorhabditis elegans. Nature 450: 63-70. 
Chalasani SH, Kato S, Albrecht DR, Nakagawa T, Abbott LF, Bargmann CI. 2010. Neuropeptide feedback modifies odorevoked dynamics in Caenorhabditis elegans olfactory neurons. Nat Neurosci 13: 615-621.

Chatzigeorgiou M, Yoo S, Watson JD, Lee WH, Spencer WC, Kindt KS, Hwang SW, Miller DM III, Treinin M, Driscoll M, et al. 2010. Specific roles for DEG/ENaC and TRP channels in touch and thermosensation in C. elegans nociceptors. Nat Neurosci 13: 861-868.

Chi CA, Clark DA, Lee S, Biron D, Luo L, Gabel CV, Brown J, Sengupta P, Samuel AD. 2007. Temperature and food mediate long-term thermotactic behavioral plasticity by association-independent mechanisms in C. elegans. I Exp Biol 210: 4043-4052.

Chung SH, Clark DA, Gabel CV, Mazur E, Samuel AD. 2006. The role of the AFD neuron in C. elegans thermotaxis analyzed using femtosecond laser ablation. BMC Neurosci 7: 30. doi: 10.1186/1471-2202-7-30.

Clark DA, Biron D, Sengupta P, Samuel ADT. 2006. The AFD sensory neurons encode multiple functions underlying thermotactic behavior in C. elegans. J Neurosci 26: 7444-7451.

Clark DA, Gabel CV, Gabel H, Samuel AD. 2007a. Temporal activity patterns in thermosensory neurons of freely moving Caenorhabditis elegans encode spatial thermal gradients. I Neurosci 27: 6083-6090.

Clark DA, Gabel CV, Lee TM, Samuel AD. 2007b. Short-term adaptation and temporal processing in the cryophilic response of Caenorhabditis elegans. J Neurophysiol 97: 1903-1910.

Coburn C, Bargmann CI. 1996. A putative cyclic nucleotidegated channel is required for sensory development and function in C. elegans. Neuron 17: 695-706.

Colosimo ME, Brown A, Mukhopadhyay S, Gabel C, Lanjuin $\mathrm{AE}$, Samuel AD, Sengupta P. 2004. Identification of thermosensory and olfactory neuron-specific genes via expression profiling of single neuron types. Curr Biol 14: 2245-2251.

Conti B, Sanchez-Alavez M, Winsky-Sommerer R, Morale MC, Lucero J, Brownell S, Fabre V, Huitron-Resendiz S, Henriksen S, Zorrilla EP, et al. 2006. Transgenic mice with a reduced core body temperature have an increased life span. Science 314: $825-828$.

Damann N, Voets T, Nilius B. 2008. TRPs in our senses. Curr Biol 18: R880-R889. doi: 10.1016/j.cub.2008.07.063.

Deal J. 1941. The temperature preferendum of certain insects. J Anim Ecol 10: 323-356.

Dhaka A, Viswanath V, Patapoutian A. 2006. TRP ion channels and temperature sensation. Annu Rev Neurosci 29: 135-161.

Dillon ME, Wang G, Garrity PA, Huey RB. 2009. Review: Thermal preference in Drosophila. J Therm Biol 34: 109-119.

Duistermars BJ, Chow DM, Frye MA. 2009. Flies require bilateral sensory input to track odor gradients in flight. Curr Biol 19: 1301-1307.

Dusenbery DB, Barr J. 1980. Thermal limits and chemotaxis in mutants of the nematode Caenorhabditis elegans defective in thermotaxis. J Comp Physiol 137: 353-356.

Dusenbery DB, Sheridan RE, Russell RL. 1975. Chemotaxisdefective mutants of the nematode Caenorhabditis elegans. Genetics 80: 297-309.

Etchberger JF, Lorch A, Sleumer MC, Zapf R, Jones SJ, Marra MA, Holt RA, Moerman DG, Hobert O. 2007. The molecular signature and cis-regulatory architecture of a C. elegans gustatory neuron. Genes Dev 21: 1653-1674.

Fry SN, Sayaman R, Dickinson MH. 2005. The aerodynamics of hovering flight in Drosophila. J Exp Biol 208: 2303-2318.

Fry SN, Rohrseitz N, Straw AD, Dickinson MH. 2008. TrackFly: Virtual reality for a behavioral system analysis in free-flying fruit flies. J Neurosci Methods 171: 110-117.
Fry SN, Rohrseitz N, Straw AD, Dickinson MH. 2009. Visual control of flight speed in Drosophila melanogaster. J Exp Biol 212: $1120-1130$.

Fu Y, Yau KW. 2007. Phototransduction in mouse rods and cones. Pflugers Arch 454: 805-819.

Galbadage T, Hartman PS. 2008. Repeated temperature fluctuation extends the life span of Caenorhabditis elegans in a daf-16-dependent fashion. Mech Ageing Dev 129: 507514.

Gerisch B, Antebi A. 2004. Hormonal signals produced by DAF-9/ cytochrome $\mathrm{P} 450$ regulate $C$. elegans dauer diapause in response to environmental cues. Development 131: 1765-1776.

Gerisch B, Weitzel C, Kober-Eisermann C, Rottiers V, Antebi A. 2001. A hormonal signaling pathway influencing C. elegans metabolism, reproductive development, and life span. Dev Cell 1: 841-851.

Golden JW, Riddle DL. 1982. A pheromone influences larval development in the nematode Caenorhabditis elegans. Science 218: $578-580$.

Golden JW, Riddle DL. 1984a. A pheromone-induced developmental switch in Caenorhabditis elegans: Temperaturesensitive mutants reveal a wild-type temperature-dependent process. Proc Natl Acad Sci 81: 819-823.

Golden JW, Riddle DL. 1984b. The Caenorhabditis elegans dauer larva: Developmental effects of pheromone, food, and temperature. Dev Biol 102: 368-378.

Gomez M, De Castro E, Guarin E, Sasakura H, Kuhara A, Mori I, Bartfai T, Bargmann CI, Nef P. 2001. $\mathrm{Ca}^{2+}$ signaling via the neuronal calcium sensor-1 regulates associative learning and memory in C. elegans. Neuron 30: 241-248.

Goodman MB, Schwarz EM. 2003. Transducing touch in Caenorhabditis elegans. Annu Rev Physiol 65: 429-452.

Gray JM, Hill JJ, Bargmann CI. 2005. A circuit for navigation in Caenorhabditis elegans. Proc Natl Acad Sci 102: 3184-3191.

Hamada FN, Rosenzweig M, Kang K, Pulver SR, Ghezzi A, Jegla TJ, Garrity PA. 2008. An internal thermal sensor controlling temperature preference in Drosophila. Nature 454: $217-220$.

Hardie R, Minke B. 1992. The trp gene is essential for a lightactivated $\mathrm{Ca}^{2+}$ channel in Drosophila photoreceptors. Neuron 8: 643-651.

Hart A, Sims S, Kaplan J. 1995. Synaptic code for sensory modalities revealed by C. elegans GLR-1 glutamate receptor. Nature 378: 82-85.

Harvey SC, Viney ME. 2007. Thermal variation reveals natural variation between isolates of Caenorhabditis elegans. I Exp Zoolog B Mol Dev Evol 308: 409-416.

Hastings JW, Sweeney BM. 1957. On the mechanism of temperature independence in a biological clock. Proc Natl Acad Sci 43: 804-811.

Hedgecock EM, Russell RL. 1975. Normal and mutant thermotaxis in the nematode Caenorhabditis elegans. Proc Natl Acad Sci 72: 4061-4065.

Heinrich B. 1993. The hot-blooded insects: Strategies and mechanisms of thermoregulation. Harvard University Press, Cambridge, MA.

Hensel H. 1973. Neural processes in thermoregulation. Physiol Rev 53: 948-1017.

Hobert O, Mori I, Yamashita Y, Honda H, Ohshima Y, Liu Y, Ruvkun G. 1997. Regulation of interneuron function in the C. elegans thermoregulatory pathway by the ttx-3 LIM homeobox gene. Neuron 19: 345-357.

Hoffmann AA. 2010. Physiological climatic limits in Drosophila: Patterns and implications. J Exp Biol 213: 870-880.

Hong ST, Bang S, Paik D, Kang J, Hwang S, Jeon K, Chun B, Hyun S, Lee Y, Kim J. 2006. Histamine and its receptors 
modulate temperature-preference behaviors in Drosophila. J Neurosci 26: 7245-7256.

Hong ST, Bang S, Hyun S, Kang J, Jeong K, Paik D, Chung J, Kim J. 2008. cAMP signalling in mushroom bodies modulates temperature preference behaviour in Drosophila. Nature 454: 771-775.

Hosono R, Mitsui Y, Sato Y, Aizawa S, Miwa J. 1982. Life span of the wild and mutant nematode Caenorhabditis elegans. Effects of sex, sterilization, and temperature. Exp Gerontol 17: $163-172$.

Huey RB, Hertz PE, Sinervo B. 2003. Behavioral drive versus behavioral inertia in evolution: A null model approach. Am Nat 161: 357-366.

Iino Y, Yoshida K. 2009. Parallel use of two behavioral mechanisms for chemotaxis in Caenorhabditis elegans. I Neurosci 29: $5370-5380$.

Inada $\mathrm{H}$, Ito $\mathrm{H}$, Satterlee J, Sengupta P, Matsumoto K, Mori I. 2006. Identification of guanylyl cyclases that function in thermosensory neurons of Caenorhabditis elegans. Genetics 172: 2239-2252.

Ito $\mathrm{H}$, Inada H, Mori I. 2006. Quantitative analysis of thermotaxis in the nematode Caenorhabditis elegans. I Neurosci Methods 154: 45-52.

Jeong PY, Jung M, Yim YH, Kim H, Park M, Hong E, Lee W, Kim YH, Kim K, Paik YK. 2005. Chemical structure and biological activity of the Caenorhabditis elegans dauerinducing pheromone. Nature 433: 541-545.

Jia K, Albert PS, Riddle DL. 2002. DAF-9, a cytochrome P450 regulating C. elegans larval development and adult longevity. Development 129: 221-231.

Jurado P, Kodama E, Tanizawa Y, Mori I. 2010. Distinct thermal migration behaviors in response to different thermal gradients in Caenorhabditis elegans. Genes Brain Behav 9: 120-127.

Kang K, Pulver SR, Panzano VC, Chang EC, Griffith LC, Theobald DL, Garrity PA. 2010. Analysis of Drosophila TRPA1 reveals an ancient origin for human chemical nociception. Nature 464: 597-600.

Katsov AY, Clandinin TR. 2008. Motion processing streams in Drosophila are behaviorally specialized. Neuron 59: 322-335.

Kimura KD, Miyawaki A, Matsumoto K, Mori I. 2004. The $C$. elegans thermosensory neuron AFD responds to warming. Curr Biol 14: 1291-1295.

Klass MR. 1977. Aging in the nematode Caenorhabditis elegans: Major biological and environmental factors influencing life span. Mech Ageing Dev 6: 413-429.

Kodama E, Kuhara A, Mohri-Shiomi A, Kimura KD, Okumura M, Tomioka M, Iino Y, Mori I. 2006. Insulin-like signaling and the neural circuit for integrative behavior in C. elegans. Genes Dev 20: 2955-2960.

Komatsu H, Mori I, Ohshima Y. 1996. Mutations in a cyclic nucleotide-gated channel lead to abnormal thermosensation and chemosensation in C. elegans. Neuron 17: 707-718.

Komatsu H, Jin YH, L'Etoile N, Mori I, Bargmann CI, Akaike N, Ohshima Y. 1999. Functional reconstitution of a heteromeric cyclic nucleotide-gated channel of Caenorhabditis elegans in cultured cells. Brain Res 821: 160-168.

Krochmal AR, Bakken GS. 2003. Thermoregulation is the pits: Use of thermal radiation for retreat site selection by rattlesnakes. J Exp Biol 206: 2539-2545.

Krstevska B, Hoffmann AA. 1994. The effects of acclimation and rearing conditions on the response of tropical and temperate populations of Drosophila melanogaster and D. simulans to a temperature gradient (Diptera: Drosophilidae). I Insect Behav 7: 279-288.

Kuhara A, Mori I. 2006. Molecular physiology of the neural circuit for calcineurin-dependent associative learning in Caenorhabditis elegans. J Neurosci 26: 9355-9364.
Kuhara A, Inada H, Katsura I, Mori I. 2002. Negative regulation and gain control of sensory neurons by the C. elegans calcineurin TAX-6. Neuron 33: 751-763.

Kuhara A, Okumura M, Kimata T, Tanizawa Y, Takano R, Kimura KD, Inada H, Matsumoto K, Mori I. 2008. Temperature sensing by an olfactory neuron in a circuit controlling behavior of C. elegans. Science 320: 803-807.

Kwon Y, Shim HS, Wang X, Montell C. 2008. Control of thermotactic behavior via coupling of a TRP channel to a phospholipase C signaling cascade. Nat Neurosci 11: 871873.

Kwon Y, Shen WL, Shim HS, Montell C. 2010. Fine thermotactic discrimination between the optimal and slightly cooler temperatures via a TRPV channel in chordotonal neurons. J Neurosci 30: 10465-10471.

Lee SJ, Kenyon C. 2009. Regulation of the longevity response to temperature by thermosensory neurons in Caenorhabditis elegans. Curr Biol 19: 715-722.

Lee RY, Sawin ER, Chalfie M, Horvitz HR, Avery L. 1999. EAT-4, a homolog of a mammalian sodium-dependent inorganic phosphate cotransporter, is necessary for glutamatergic neurotransmission in Caenorhabditis elegans. I Neurosci 19: 159-167.

Lee Y, Lee Y, Lee J, Bang S, Hyun S, Kang J, Hong ST, Bae E, Kaang BK, Kim J. 2005. Pyrexia is a new thermal transient receptor potential channel endowing tolerance to high temperatures in Drosophila melanogaster. Nat Genet 37: 305-310.

Leon LR. 2005. The use of gene knockout mice in thermoregulation studies. I Therm Biol 30: 273-288.

Li C, Nelson LS, Kim K, Nathoo A, Hart AC. 1999. Neuropeptide gene families in the nematode Caenorhabditis elegans. Ann N Y Acad Sci 897: 239-252.

Liu L, Yermolaieva O, Johnson WA, Abboud FM, Welsh MJ. 2003. Identification and function of thermosensory neurons in Drosophila larvae. Nat Neurosci 6: 267-273.

Liu J, Ward A, Gao J, Dong Y, Nishio N, Inada H, Kang L, Yu Y, $\mathrm{Ma} \mathrm{D}, \mathrm{Xu} \mathrm{T}$, et al. 2010. C. elegans phototransduction requires a $G$ protein-dependent cGMP pathway and a taste receptor homolog. Nat Neurosci 13: 715-722.

Louis M, Huber T, Benton R, Sakmar TP, Vosshall LB. 2008. Bilateral olfactory sensory input enhances chemotaxis behavior. Nat Neurosci 11: 187-199.

Luo L, Clark DA, Biron D, Mahadevan L, Samuel AD. 2006. Sensorimotor control during isothermal tracking in Caenorhabditis elegans. I Exp Biol 209: 4652-4662.

Luo L, Gabel CV, Ha HI, Zhang Y, Samuel AD. 2008. Olfactory behavior of swimming $C$. elegans analyzed by measuring motile responses to temporal variations of odorants. J Neurophysiol 99: 2617-2625.

Luo L, Gershow M, Rosenzweig M, Kang K, Fang-Yen C, Garrity PA, Samuel AD. 2010. Navigational decision making in Drosophila thermotaxis. I Neurosci 30: 42614272.

Mak HY, Ruvkun G. 2004. Intercellular signaling of reproductive development by the C. elegans DAF-9 cytochrome P450. Development 131: 1777-1786.

Maricq AV, Peckol E, Bargmann CI. 1995. Mechanosensory signalling in C.elegans mediated by the GLR-1 glutamate receptor. Nature 378: 78-81.

McKay RR, Chen DM, Miller K, Kim S, Stark WS, Shortridge RD. 1995. Phospholipase C rescues visual defect in norpA mutant of Drosophila melanogaster. I Biol Chem 270: 13271-13276.

Mohri A, Kodama E, Kimura KD, Koike M, Mizuno T, Mori I. 2005. Genetic control of temperature preference in the nematode Caenorhabditis elegans. Genetics 169: 1437-1450. 
Mori I. 1999. Genetics of chemotaxis and thermotaxis in the nematode Caenorhabditis elegans. Annu Rev Genet 33: 399422.

Mori I, Ohshima Y. 1995. Neural regulation of thermotaxis in Caenorhabditis elegans. Nature 376: 344-348.

Motola DL, Cummins CL, Rottiers V, Sharma KK, Li T, Li Y, Suino-Powell K, Xu HE, Auchus RJ, Antebi A, et al. 2006. Identification of ligands for DAF-12 that govern dauer formation and reproduction in C. elegans. Cell 124: 1209-1223.

Murakami H, Bessinger K, Hellmann J, Murakami S. 2005. Agingdependent and -independent modulation of associative learning behavior by insulin/insulin-like growth factor-1 signal in Caenorhabditis elegans. J Neurosci 25: 10894-10904.

Nakazato K, Mochizuki A. 2009. Steepness of thermal gradient is essential to obtain a unified view of thermotaxis in $C$. elegans. J Theor Biol 260: 56-65.

Nathoo AN, Moeller RA, Westlund BA, Hart AC. 2001. Identification of neuropeptide-like protein gene families in Caenorhabditis elegans and other species. Proc Natl Acad Sci 98: 14000-14005.

Niemeyer BA, Suzuki E, Scott K, Jalink K, Zuker CS. 1996. The Drosophila light-activated conductance is composed of the two channels TRP and TRPL. Cell 85: 651-659.

Noroozi M, Azmi BZ, Wahab ZA, Moksin MM, Mamat MH. 2009. Thermal diffusivity determination of liquid through thermal diffusion length measurement. Solid State Sci Technol 17: 44-49.

Okochi Y, Kimura KD, Ohta A, Mori I. 2005. Diverse regulation of sensory signaling by C. elegans nPKC- $\varepsilon / \eta$ TTX-4. EMBO J 24: 2127-2137.

Perkins LA, Hedgecock EM, Thomson JN, Culotti JG. 1986. Mutant sensory cilia in the nematode Caenorhabditis elegans. Dev Biol 117: 456-487.

Pierce-Shimomura JT, Morse TM, Lockery SR. 1999. The fundamental role of pirouettes in Caenorhabditis elegans chemotaxis. J Neurosci 19: 9557-9569.

Pittendrigh CS. 1954. On temperature independence in the clock system controlling emergence time in Drosophila. Proc Natl Acad Sci 40: 1018-1029.

Prahlad V, Cornelius T, Morimoto RI. 2008. Regulation of the cellular heat shock response in Caenorhabditis elegans by thermosensory neurons. Science 320: 811-814.

Pungaliya C, Srinivasan J, Fox BW, Malik RU, Ludewig AH, Sternberg PW, Schroeder FC. 2009. A shortcut to identifying small molecule signals that regulate behavior and development in Caenorhabditis elegans. Proc Natl Acad Sci 106: 7708-7713.

Ramot D, MacInnis BL, Goodman MB. 2008a. Bidirectional temperature-sensing by a single thermosensory neuron in C. elegans. Nat Neurosci 11: 908-915.

Ramot D, MacInnis BL, Lee HC, Goodman MB. 2008b. Thermotaxis is a robust mechanism for thermoregulation in Caenorhabditis elegans nematodes. I Neurosci 28: 1254612557.

Rosenzweig M, Brennan KM, Tayler TD, Phelps PO, Patapoutian A, Garrity PA. 2005. The Drosophila ortholog of vertebrate TRPA1 regulates thermotaxis. Genes Dev 19: 419-424.

Rosenzweig M, Kang K, Garrity PA. 2008. Distinct TRP channels are required for warm and cool avoidance in Drosophila melanogaster. Proc Natl Acad Sci 105: 14668-14673.

Ryu WS, Samuel AD. 2002. Thermotaxis in Caenorhabditis elegans analyzed by measuring responses to defined thermal stimuli. J Neurosci 22: 5727-5733.

Sarin S, Prabhu S, O'Meara MM, Pe'er I, Hobert O. 2008. Caenorhabditis elegans mutant allele identification by whole-genome sequencing. Nat Methods 5: 865-867.
Satterlee JS, Sasakura H, Kuhara A, Berkeley M, Mori I, Sengupta P. 2001. Specification of thermosensory neuron fate in C. elegans requires $t$ tx-1, a homolog of otd/Otx. Neuron 31: 943-956.

Sayeed O, Benzer S. 1996. Behavioral genetics of thermosensation and hygrosensation in Drosophila. Proc Natl Acad Sci 93: 6079-6084.

Sehadova H, Glaser FT, Gentile C, Simoni A, Giesecke A, Albert JT, Stanewsky R. 2009. Temperature entrainment of Drosophila's circadian clock involves the gene nocte and signaling from peripheral sensory tissues to the brain. Neuron 64: 251-266.

Shaw RF, Bercaw BL. 1962. Temperature and life-span in poikilothermous animals. Nature 196: 454-457.

Shen Y, Sarin S, Liu Y, Hobert O, Pe'er I. 2008. Comparing platforms for $C$. elegans mutant identification using highthroughput whole-genome sequencing. PLOS ONE 3: e4012. doi: 10.1371/journal.pone.0004012.

Siddiqui WH, Barlow CA. 1972. Population growth of Drosophila melanogaster (Diptera: Drosophilidae) at constant and alternating temperatures. Ann Entomol Soc Am 65: 993-1001.

Simon E, Pierau FK, Taylor DC. 1986. Central and peripheral thermal control of effectors in homeothermic temperature regulation. Physiol Rev 66: 235-300.

Sokabe T, Tsujiuchi S, Kadowaki T, Tominaga M. 2008. Drosophila painless is a $\mathrm{Ca}^{2+}$-requiring channel activated by noxious heat. J Neurosci 28: 9929-9938.

Stephens GJ, Johnson-Kerner B, Bialek W, Ryu WS. 2008. Dimensionality and dynamics in the behavior of C. elegans. PLoS Comput Biol 4: e1000028. doi: 10.1371/journal.pcbi. 1000028.

Stevenson RD. 1985. The relative importance of behavioral and physiological adjustments controlling body temperature in terrestrial ectotherms. Am Nat 126: 362-386.

Sun Y, Liu L, Ben-Shahar Y, Jacobs JS, Eberl DF, Welsh MJ. 2009. TRPA channels distinguish gravity sensing from hearing in Johnston's organ. Proc Natl Acad Sci 106: 13606-13611.

Thomsen E, Thomsen M. 1937. Uber das thermopraferendum der larven einiger fliegenarten. Z Vgl Physiol 24: 343-380.

Tissenbaum HA, Hawdon J, Perregaux M, Hotez P, Guarente L, Ruvkun G. 2000. A common muscarinic pathway for diapause recovery in the distantly related nematode species Caenorhabditis elegans and Ancylostoma caninum. Proc Natl Acad Sci 97: 460-465.

Tominaga M, Caterina MJ. 2004. Thermosensation and pain. I Neurobiol 61: 3-12.

Tracey WD Jr, Wilson RI, Laurent G, Benzer S. 2003. painless, a Drosophila gene essential for nociception. Cell 113: 261-273.

Tsalik EL, Hobert O. 2003. Functional mapping of neurons that control locomotory behavior in Caenorhabditis elegans. J Neurobiol 56: 178-197.

Vermeulen CJ, Bijlsma R. 2004. Changes in mortality patterns and temperature dependence of lifespan in Drosophila melanogaster caused by inbreeding. Heredity 92: 275-281.

Viswanath V, Story GM, Peier AM, Petrus MJ, Lee VM, Hwang SW, Patapoutian A, Jegla T. 2003. Opposite thermosensor in fruitfly and mouse. Nature 423: 822-823.

Wakabayashi T, Kitagawa I, Shingai R. 2004. Neurons regulating the duration of forward locomotion in Caenorhabditis elegans. Neurosci Res 50: 103-111.

Ward A, Liu J, Feng Z, Xu XZ. 2008. Light-sensitive neurons and channels mediate phototaxis in C. elegans. Nat Neurosci 11: 916-922.

Wenick AS, Hobert O. 2004. Genomic cis-regulatory architecture and trans-acting regulators of a single interneuronspecific gene battery in C. elegans. Dev Cell 6: 757-770. 


\section{Garrity et al.}

White JG, Southgate E, Thomson JN, Brenner S. 1986. The structure of the nervous system of the nematode Caenorhabditis elegans. Philos Trans $R$ Soc Lond B 314: 1-340.

Xu SY, Cang CL, Liu XF, Peng YQ, Ye YZ, Zhao ZQ, Guo AK. 2006. Thermal nociception in adult Drosophila: Behavioral characterization and the role of the painless gene. Genes Brain Behav 5: 602-613.

Xu J, Sornborger AT, Lee JK, Shen P. 2008. Drosophila TRPA channel modulates sugar-stimulated neural excitation, avoidance and social response. Nat Neurosci 11: 676-682.

Yamada Y, Ohshima Y. 2003. Distribution and movement of Caenorhabditis elegans on a thermal gradient. I Exp Biol 206: 2581-2593.

Yau KW, Hardie RC. 2009. Phototransduction motifs and variations. Cell 139: 246-264.

Zariwala HA, Miller AC, Faumont S, Lockery SR. 2003. Step response analysis of thermotaxis in Caenorhabditis elegans. I Neurosci 23: 4369-4377.

Zhang F, Wang LP, Brauner M, Liewald JF, Kay K, Watzke N, Wood PG, Bamberg E, Nagel G, Gottschalk A, et al. 2007. Multimodal fast optical interrogation of neural circuitry. Nature 446: 633-639. 


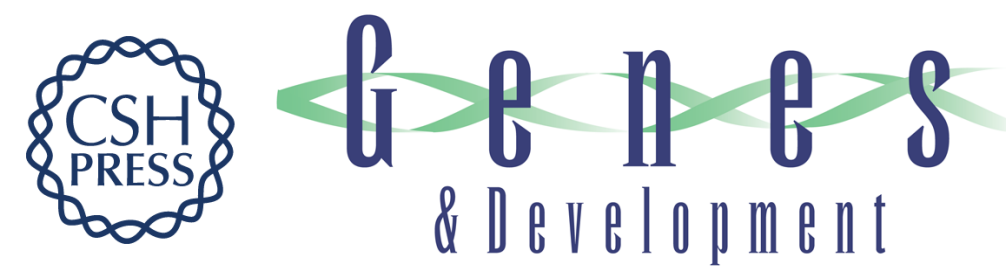

\title{
Running hot and cold: behavioral strategies, neural circuits, and the molecular machinery for thermotaxis in C. elegans and Drosophila
}

\author{
Paul A. Garrity, Miriam B. Goodman, Aravinthan D. Samuel, et al.
}

Genes Dev. 2010, 24:

Access the most recent version at doi:10.1101/gad.1953710

$\begin{array}{ll}\text { References } & \begin{array}{l}\text { This article cites } 142 \text { articles, } 47 \text { of which can be accessed free at: } \\ \text { http://genesdev.cshlp.org/content/24/21/2365.full.html\#ref-list-1 }\end{array}\end{array}$

License

Email Alerting Receive free email alerts when new articles cite this article - sign up in the box at the top Service right corner of the article or click here.

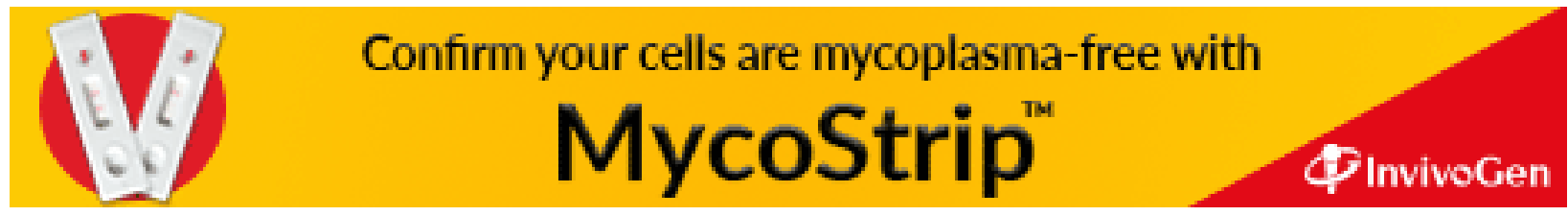

